\title{
The Impact of Preceding Spring Antarctic Oscillation on the Variations of Lake Ice Phenology over the Tibetan Plateau ${ }^{\mathscr{O}}$
}

\author{
YONG LIU \\ Nansen-Zhu International Research Centre, Institute of Atmospheric Physics, Chinese Academy of Sciences, and \\ University of Chinese Academy of Sciences, Beijing, China \\ HuOPO CHEN \\ Nansen-Zhu International Research Centre, Institute of Atmospheric Physics, Chinese Academy of Sciences, \\ Beijing, and Collaborative Innovation Center on Forecast and Evaluation of Meteorological Disasters, \\ Nanjing University for Information Science and Technology, Nanjing, and Joint Laboratory of Climate \\ and Environment Change, Chengdu University of Information Technology, Chengdu, China

\section{HUIXIN LI} \\ Collaborative Innovation Center on Forecast and Evaluation of Meteorological Disasters, \\ Nanjing University for Information Science and Technology, Nanjing, China

\section{HUIJUN WANG} \\ Nansen-Zhu International Research Centre, Institute of Atmospheric Physics, Chinese Academy of Sciences, \\ Beijing, and Collaborative Innovation Center on Forecast and Evaluation of Meteorological Disasters, \\ Nanjing University for Information Science and Technology, Nanjing, China
}

(Manuscript received 10 February 2019, in final form 3 October 2019)

\begin{abstract}
The lake ice phenology response to climate change has been receiving growing concern in recent years. However, most studies have put emphasis on the spatial and temporal variability of lake ice phenology, and relatively few studies have been devoted to investigating the physical mechanisms of changes in lake ice phenology from the perspective of climatic dynamics. This study investigates the possible impact of the Antarctic Oscillation (AAO) on the variations in lake ice phenology over the Tibetan Plateau (TP). The results show that there is an intimate relationship between the AAO and the variations in break-up/ice duration during the period 2003-15. Further analysis indicates that the preceding boreal spring AAO-induced atmospheric circulation anomalies are favorable for generating tropical South Atlantic Ocean SST anomalies through air-sea interaction. Then the tropical SST anomalies strengthen the anomalous localscale meridional-vertical circulation that projects into the Azores high and further induce the extratropical portion of the North Atlantic SST tripole. The anomalous warm core in the North Atlantic serves as the source of wave activity flux and stimulates a stationary wave train along the Eurasian continent to change the downstream atmospheric circulation. As a response, an abnormal cyclone and enhanced updraft are triggered over the TP, which are favorable for the formation of snowfall and then lower the surface air temperature according to the snow-albedo feedback mechanism, and thus result in the prolonged lake ice duration events. This study provides a new insight to link the AAO influence and climate over the TP and is helpful to understand the changes in lake ice phenology in response to climate change in recent years.
\end{abstract}

Supplemental information related to this paper is available at the Journals Online website: https://doi.org/10.1175/JCLI-D-190111.s1.

Corresponding author: Chen Huopo, chenhuopo@mail.iap.ac.cn

\section{Introduction}

The Tibetan Plateau (TP), which is regarded as one of the most sensitive areas for climate warming in the world, in turn exerts great influence on regional and global climate (Chakraborty et al. 2002; Duan et al. 2012; Liu et al.

DOI: $10.1175 /$ JCLI-D-19-0111.1

(c) 2019 American Meteorological Society. For information regarding reuse of this content and general copyright information, consult the AMS Copyright Policy (www.ametsoc.org/PUBSReuseLicenses). 


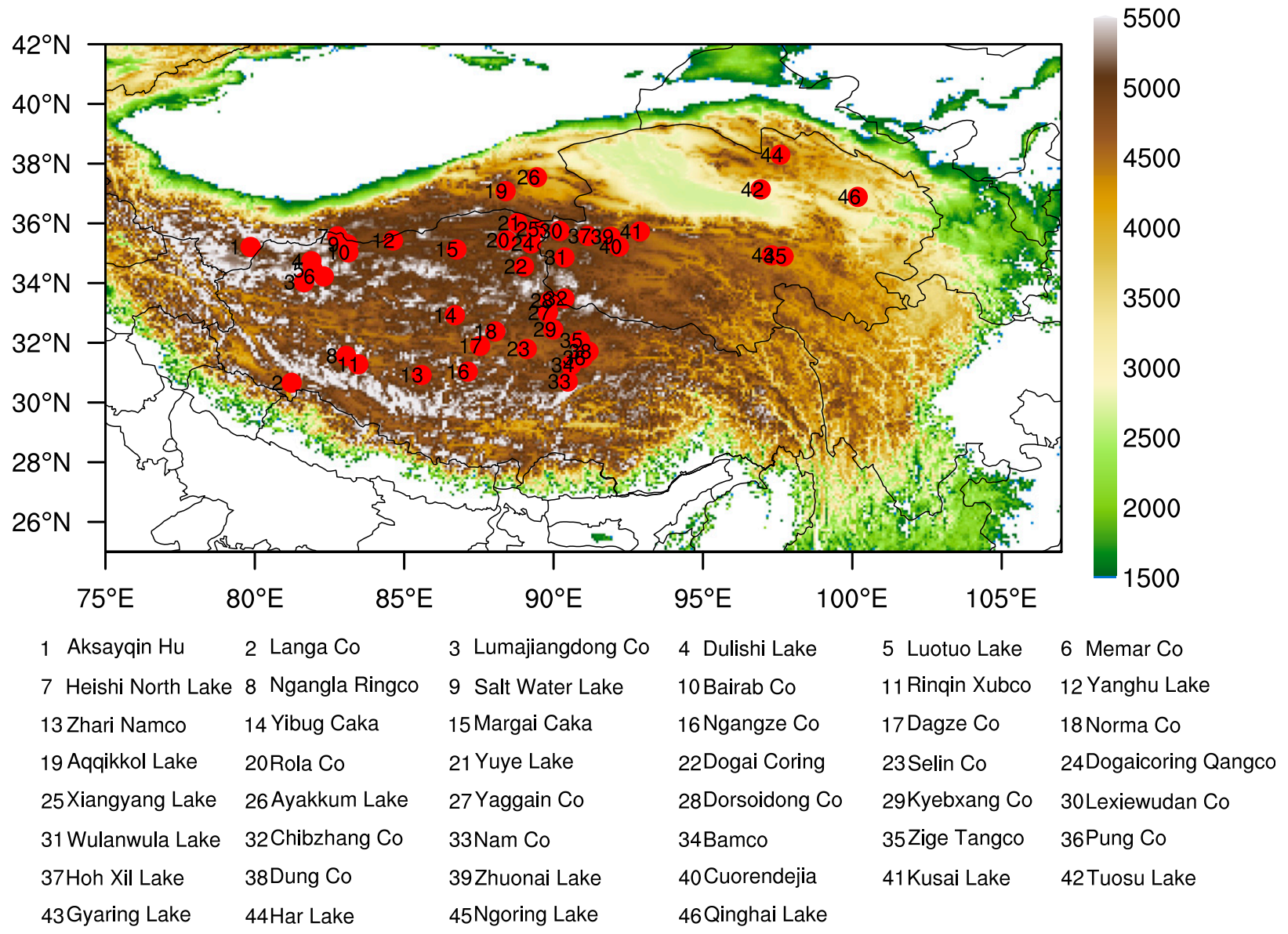

FIG. 1. Topographic map (shading; $\mathrm{m}$ ) and geographic location of the 46 lakes (red circles) with extent exceeding $100 \mathrm{~km}^{2}$ over the Tibetan Plateau.

2014; Rangwala et al. 2009; Shaman and Tziperman 2005). One distinct effect is that the TP can change atmospheric circulation over the Asian monsoon region through strong thermal forcing, and thus impact the intensity of monsoon precipitation in eastern China (Hsu and Liu 2003; Yang et al. 2014). In addition, the glacier, the snow cover, and the lakes over the TP (Fig. 1) supply water sources to adjacent river basins, and greatly affect the hydrometeorology and freshwater ecosystems around the Asian river basins (e.g., Yang et al. 2014). In the context of global warming, the TP experiences significant climate changes and further reshapes the local ecosystem and environment (e.g., Guo et al. 2018; Hua et al. 2017; Liu et al. 2019b; Su et al. 2013; Zhang et al. 2013). Some studies have pointed out that the climate over the TP significantly responds well to the warming trend in recent decades, which is directly reflected in the cryosphere (Xu et al. 2017; Yao et al. 2012). However, most of these studies merely put more focus on the changes in glaciers, permafrost, and snow cover (e.g., Xu et al. 2017; Yao et al. 2012). A comparatively small number of studies have concentrated on the statistical characteristics of lake ice phenology and have rarely involved climate dynamic analysis. Actually, lake ice phenology has been treated as a direct proxy to regional climate change, and in some case, the variations in lake ice phenology can be regarded as a more robust indicator than the temperature in winter (Latifovic and Pouliot 2007; Livingstone 1997; Robertson et al. 1992).

An increasing number of studies have demonstrated that lake ice cover can exert great influences on regional climate, ecological system, and hydrological cycles (e.g., Du et al. 2018; Rouse et al. 2005). For example, Latifovic and Pouliot (2007) have pointed out that longer ice-free periods increase the annual evaporation from the lakes and the direct heat exchange between the lake surface and the atmosphere, and prolong the time of greenhouse gases emission resulting from the chemical and biological processes. Moreover, the precipitation and regional atmospheric circulation in the lake district are closely related to the heat exchange process between lake and atmosphere (Zhu et al. 2017). In fact, the large-scale 
atmospheric circulation can also influence the variations in the rapidity of ice onset through modulating the changes in sensible heat flux between the atmosphere and surface (Todd and Mackay 2003).

Generally, the regional surface air temperature is a dominant factor in determining the lake ice formation and ablation (Sánchez-López et al. 2015), and some other climate variables, such as the regional surface wind and the precipitation, can also exert relatively important influences in ice freezing and melting processes (e.g., Liu et al. 2018; Sánchez-López et al. 2015; Wang et al. 2017). Relative to the ice break-up process, the lake ice freezing process presents a much more complicated and unpredictable situation, mainly because the freezing process is also related to the lake properties like surface area and mean depth and is dependent on the daily synoptic conditions (Korhonen 2006; Sánchez-López et al. 2015). In addition to this, some studies have also revealed that large-scale teleconnections play important roles in the limnological process (e.g., Liu et al. 2018; Todd and Mackay 2003). For example, Liu et al. (2018) have indicated that the winter North Atlantic Oscillation (NAO) can exert great influence on the lake ice phenology over the southern TP through stimulating the Rossby wave train to adjust the atmospheric circulations. Meanwhile, it is found that the variability in the freeze-up date over Lake Qinghai also presented a close relationship with the declined Arctic sea ice in November (Liu et al. 2019a). It is evident that lake ice phenology can be seen as a proxy for climate change mainly because the lake ice cover responds strongly to regional temperature variability (e.g., Cai et al. 2017; Todd and Mackay 2003; Yao et al. 2016). For example, Benson et al. (2012) have found that lake ice formation and ablation dates over the Northern Hemisphere show great correspondence with the warming trend in recent decades.

There is increasing evidence that part of Northern Hemispheric climate variability originates in the Southern Hemisphere, particularly from internal atmospheric variability known as the Antarctic Oscillation. The Antarctic Oscillation (AAO), which is also known as the southern annular mode (SAM), is defined as a large-scale alternation of atmospheric mass between subtropical and subpolar in the Southern Hemisphere (Gong and Wang 1999; Thompson and Wallace 2000; Thompson et al. 2011). It has been documented that the AAO exerts remarkable influences on the precipitation (Reason and Rouault 2005; Silvestri and Vera 2003), surface temperature (Kwok and Comiso 2002), and storm track (Rao et al. 2003) in the Southern Hemisphere. In addition to this, most recent studies have revealed that the impact of the AAO is not limited to the Southern Hemisphere, and it could also extend to the Northern Hemisphere through the oceanic and atmospheric bridges (Dou and $\mathrm{Wu}$ 2018; Prabhu et al. 2016; Sun 2010; Sun et al. 2009, 2010; Zhu 2009). The sea surface temperature (SST) anomalies over Southern Ocean induced by the AAO can trigger the changes in atmospheric circulations over the Northern Hemisphere (Dou et al. 2017; Prabhu et al. 2016; Wu et al. 2015). For example, Sun et al. (2010) have indicated that the anomalous SST over the tropical South Atlantic Ocean associated with the boreal spring AAO can lead to anomalous Sahel rainfall in the early summer. Prabhu et al. (2016) have found that the negative phase of the AAO can induce a warming effect over the central equatorial Pacific region, and then weaken the monsoon rainfall over the Indian subcontinent. Moreover, the boreal spring AAO can also exert significant impact on the variation of summer rainfall over the Yangtze River valley via the convection activity over the Maritime Continent in the past decades (Sun et al. 2009). Therefore, the AAO may provide a new precursor to foreshadow the subsequent behavior of the Northern Hemisphere climates.

Then, a question arising here is whether the AAO can influence the variations of lake ice phenology over the TP in boreal spring. To address this issue, the relationship between the lake ice phenology over the TP and the AAO is first investigated and then the possible influencing process is further explored based on a newly developed dataset of TP lake ice phenology. In the following chapter, we will introduce the main data sources and statistical and dynamic methods used in this study. The main results will be provided in the text, including the dynamic mechanisms of the remote impact of the preceding boreal spring AAO on lake ice phenology over the TP. In the end, we will give a discussion and conclusions.

\section{Data and method}

\section{a. Dataset}

All of 46 lakes used here are obtained from the Science Data Bank released by Qiu et al. (2017b). The retrieved datasets span from 2002 to 2015, with an area covering more than $100 \mathrm{~km}^{2}$ for each individual lake in the TP. However, it is worth noting that the lake ice phenology was unavailable in the winter of 2011 mainly because of the satellite sensor failure. Moreover, the detailed method of how to extract lake ice phenology from the satellite data is provided by Qiu et al. (2017a).

In addition, the other datasets employed in this study are as follows: 1) The monthly SST is derived from the Hadley Centre sea ice and sea surface temperature dataset, version 1 (HadISST1), with a horizontal resolution of $1^{\circ} \times 1^{\circ}$ grid during 1979-2015 (Rayner et al. 2003). 2) The monthly atmospheric circulation data 
with a horizontal resolution of $0.75^{\circ} \times 0.75^{\circ}$ are provided by the European Centre for Medium-Range Weather Forecasts interim reanalysis (ERA-Interim) dataset (Dee et al. 2011). 3) The monthly surface heat flux and radiation flux data are obtained from the National Centers for Environmental Prediction reanalysis 2 (NCEP2) dataset (Kanamitsu et al. 2002). 4) The AAO index is retrieved from the National Oceanic and Atmospheric Administration Climate Prediction Center (http://www.cpc.ncep.noaa.gov/; Mo 2000).

\section{b. Method}

According to the definition of the satellite retrieved method, the lake ice freezing date is identified as the first date of which the lake was initially observed to be covered with ice in the cold season, and the complete lake ice ablation date is defined as the date on which the lake was observed to be completely ice-free. Hence, the statistically significant lake ice duration is defined as the number of days of which the lake was covered in ice. The preceding boreal spring (February, March, and April) refers to the season preceding complete lake ice break-up.

The correlation and regression analyses are employed to investigate the statistical relationship between meteorological variables. To highlight the interannual variability, the linear trends of both the lake ice phenology and atmospheric variables have been removed before regression analyses. In addition, we also investigated the remote impact of the preceding boreal spring AAO on the lake ice phenology using the three-dimensional wave flux proposed by Takaya and Nakamura (2001):

$$
W=\frac{P}{2|U|}\left\{\begin{array}{c}
\bar{u}\left(\psi_{x}^{\prime 2}-\psi^{\prime} \psi_{x x}^{\prime}\right)+\bar{v}\left(\psi_{x}^{\prime} \psi_{y}^{\prime}-\psi^{\prime} \psi_{x y}^{\prime}\right) \\
\bar{u}\left(\psi_{x}^{\prime} \psi_{y}^{\prime}-\psi^{\prime} \psi_{x y}^{\prime}\right)+\bar{v}\left(\psi_{y}^{\prime 2}-\psi^{\prime} \psi_{y y}^{\prime}\right) \\
\frac{f^{2}}{N^{2}}\left[\bar{u}\left(\psi_{x}^{\prime} \psi_{z}^{\prime}-\psi^{\prime} \psi_{x z}^{\prime}\right)+\bar{v}\left(\psi_{y}^{\prime} \psi_{z}^{\prime}-\psi^{\prime} \psi_{y z}^{\prime}\right)\right]
\end{array}\right\},
$$

where $U$ denotes the horizontal wind speed; $\psi$ represents the geostrophic streamfunction; $f$ means the Coriolis parameter and varies with latitude; $N^{2}=\left(R P^{\kappa} / H\right)(\partial \theta / \partial z)$ is the buoyancy frequency squared; $R$ is the gas constant for dry air; $\theta$ is the potential temperature; $P$ is defined as the pressure divided by $1000 \mathrm{hPa}$; and $\kappa$ is equal to $R$ normalized by the specific heat of air for constant pressure.

\section{Results}

\section{a. Relationship of lake ice phenology with the AAO}

Statistically, the average lake ice freeze-up date in the TP generally occurs on 14 November and the ice completely break-up date on 9 May on average, and thus the number of days of lake ice duration is 180 on average. Figure 2 presents the spatial pattern of the changing characteristics of lake ice phenology over the TP for the period of 2002-15. There is no uniform trend in the changes of lake ice phenology across the TP. However, the TP lakes show a slightly increasing trend in freezing date on average, although some lakes begin with an earlier freeze-up date. The inhomogeneous trend in freeze-up might be related to the lake internal properties, such as the lake altitude, area, depth, and salinity, as well as the special weather conditions that can individually exert important influences in the freezing process (Korhonen 2006; Sánchez-López et al. 2015). In addition, it is clear to see that most of the ablation date for TP lakes show a slightly delayed tendency, especially for the lakes over the southern TP. The result contradicts the general knowledge that the ablation date should be shifted to an earlier date due to the global warming trend. Unlike the freezing process, the lake ice melting process is closely related to the regional temperature and the mid- to high-latitude atmospheric circulation anomalies such as the NAO (Liu et al. 2018; Sánchez-López et al. 2015). Additionally, the ice breakup times for some lakes also tend to be earlier, but just limited to the region of the northern TP. Consequently, the changes in lake ice duration vary from their locations across the TP due to the inconsistent changes in freezing date and ablation time. Moreover, it should be noted that the climate over the TP would be modulated by decadal climate variability. Hence, one possible cause for this inhomogeneous trends in lake ice phenology could have been that the brevity of records neglected the important role of natural decadal climate variability.

To investigate whether the atmospheric internal variability from the Southern Hemisphere can impact the lake ice phenology over the TP, we have conducted lead-lag correlation analysis based on the index of lake ice duration date averaged over the TP. To facilitate comparison, we also conducted similar lead-lag correlation based on the index of the preceding boreal spring AAO index during the period of 2003-15. According to Fig. S1 in the online supplemental material, there is no general AAO pattern occurring over the Southern Hemisphere at 2-month lead, as based on either the AAO index or the average lake ice duration date. However, when we correlated the indices of the average lake ice duration date and the AAO with simultaneous global sea level pressure fields, the circumpolar pattern became increasingly clear and significant. The results stimulate us to investigate the possible linkage between the AAO and lake ice phenology over the TP. 


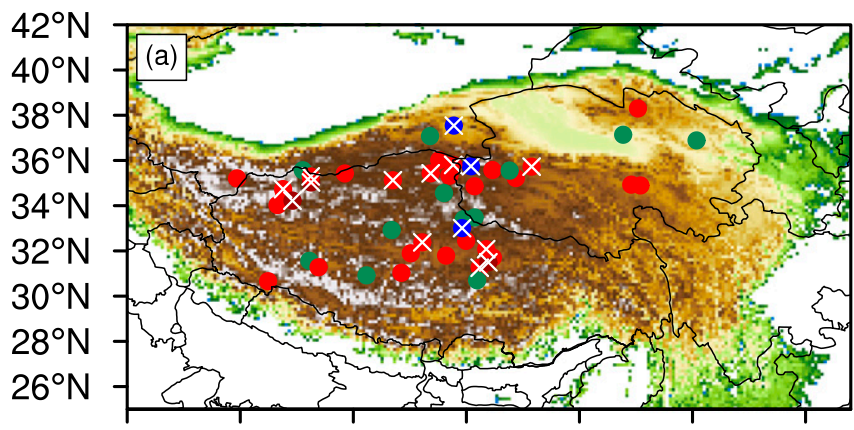

$75^{\circ} \mathrm{E} \quad 80^{\circ} \mathrm{E} \quad 85^{\circ} \mathrm{E} \quad 90^{\circ} \mathrm{E} \quad 95^{\circ} \mathrm{E} \quad 100^{\circ} \mathrm{E} \quad 105^{\circ} \mathrm{E}$

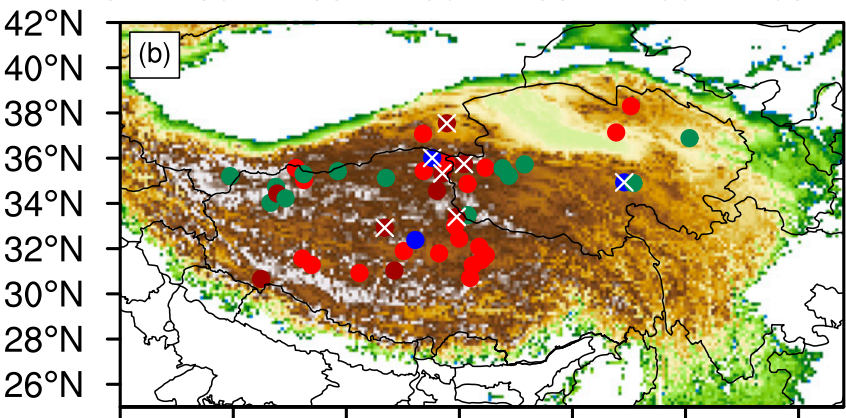

$75^{\circ} \mathrm{E} \quad 80^{\circ} \mathrm{E} \quad 85^{\circ} \mathrm{E} \quad 90^{\circ} \mathrm{E} \quad 95^{\circ} \mathrm{E} \quad 100^{\circ} \mathrm{E} \quad 105^{\circ} \mathrm{E}$

$42^{\circ} \mathrm{N}$

$40^{\circ} \mathrm{N}$
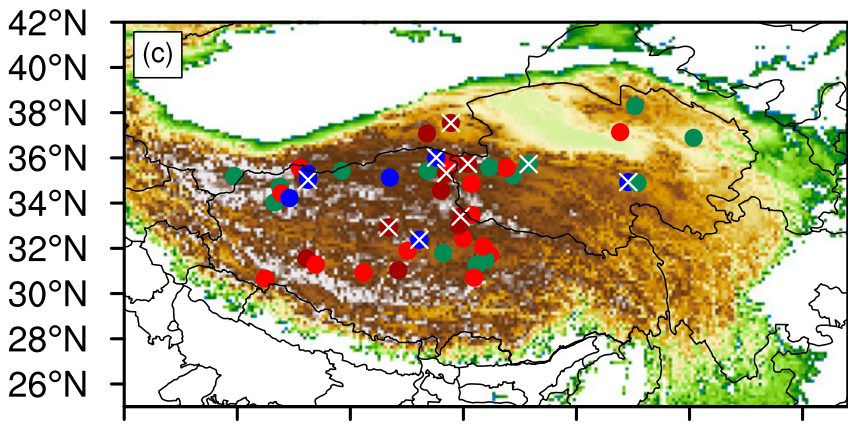

2500

4000

3500

3000

$75^{\circ} \mathrm{E} \quad 80^{\circ} \mathrm{E} \quad 85^{\circ} \mathrm{E} \quad 90^{\circ} \mathrm{E} \quad 95^{\circ} \mathrm{E} \quad 100^{\circ} \mathrm{E} \quad 105^{\circ} \mathrm{E}$

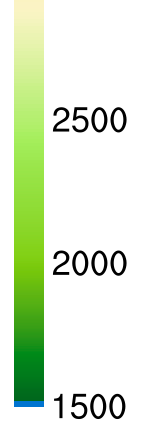

$<-1.0$

-1.0 to 0

0 to 1.0

$>1.0$

FIG. 2. The linear trend (days $\mathrm{yr}^{-1}$ ) of the lake ice (a) freeze-up date, (b) break-up date, and (c) ice duration days during 2002-15. The circle with a cross means the linear trend is significant at the $95 \%$ confidence level.

Figure 3 shows the spatial distribution of the correlations between lake ice break-up date/ice duration days and the preceding boreal spring AAO index during 2003-15. Fairly consistent positive correlations can be observed between the lake ice break-up date/ice duration days and the preceding boreal spring AAO during the past years for most lakes, especially over the western TP. Their correlations are also calculated after the winter ENSO signal removed and the positive correlations are still robust in the western TP. This implies that there is an intimate connection between lake ice phenology over the western TP and the AAO.
To further investigate the atmospheric circulation anomalies associated with ice duration at western TP lakes, the composite analysis is employed through analyzing the atmospheric difference between three prolonged ice duration years $(2003,2013$, and 2015) and three shortened ice duration years $(2007,2009$, and 2010). As indicated by Fig. 4, as a result of the anomalous cyclonic circulation dominating over the southern $\mathrm{TP}$, the northward water vapor transportation is significantly strengthened on the southern flank of TP. Consequently, the intensified southerly airflow is detained by the high mountains, which results in the ascending 
(a) BU cor. AAO

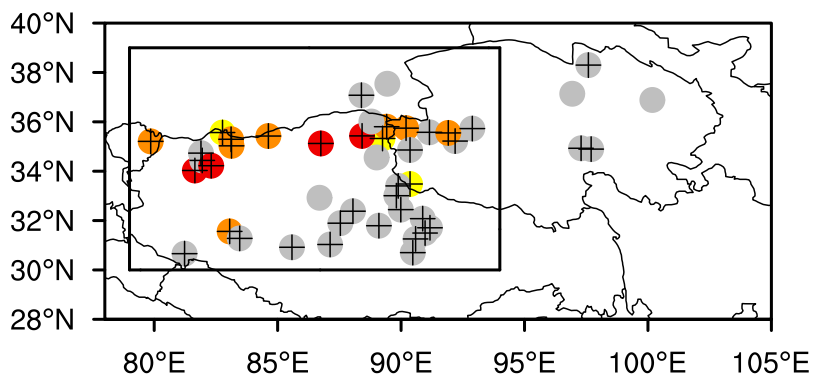

(c) ID cor. AAO

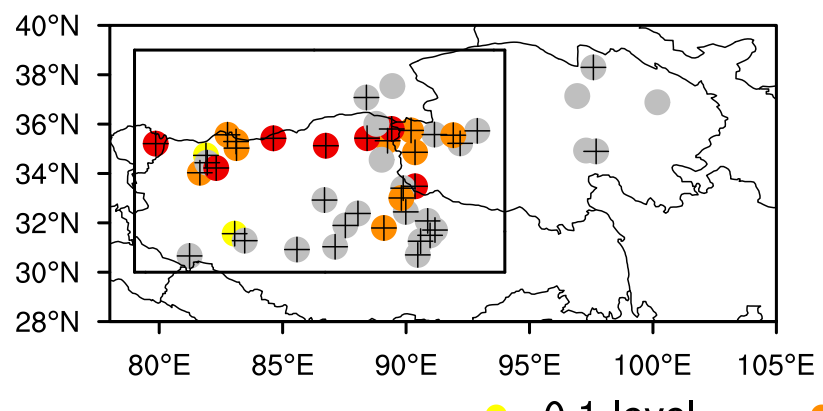

0.1-level

(e) Averaged BU cor. AAO

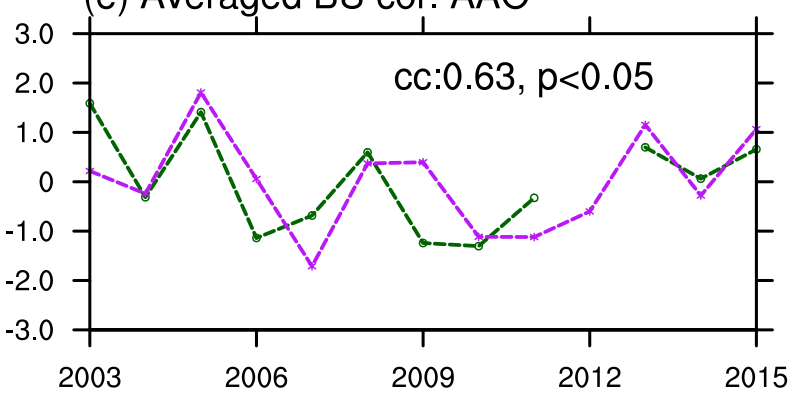

(b) ENSO removed

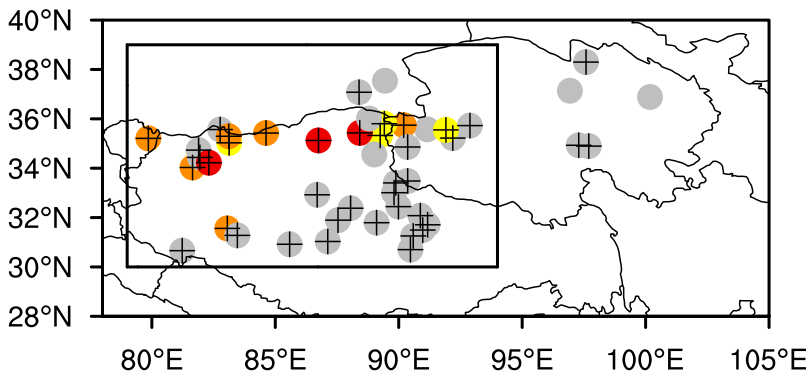

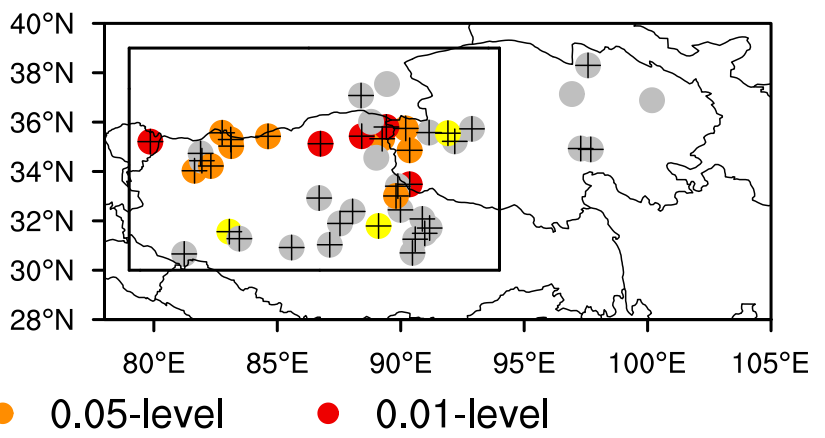

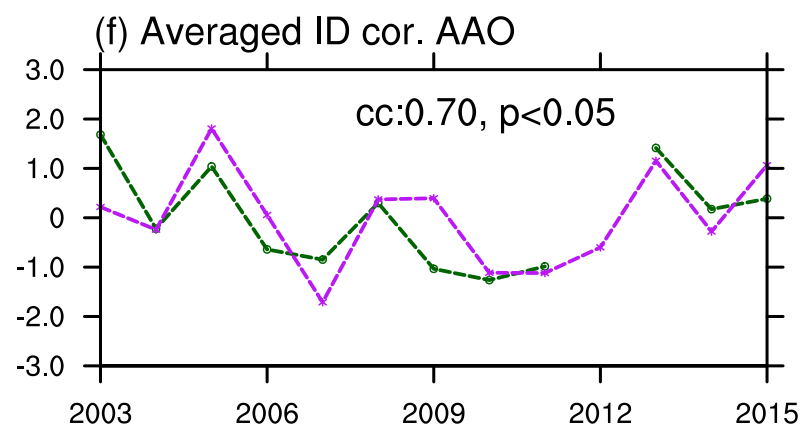

FIG. 3. The spatial distribution of the Pearson correlations between the preceding boreal spring AAO index and the (a) lake ice breakup date and (c) ice duration days; (b),(d) as in (a) and (c), but for the partial correlation after the winter ENSO signal is removed. (e),(f) The temporal series of the normalized averaged break-up date [the green curve in (e)], ice duration [the green curve in (f)], and preceding boreal spring AAO index (purple curves), respectively. The yellow, orange, and red circles in (a)-(d) mean that correlation coefficient is significant at the $90 \%, 95 \%$, and $99 \%$ confidence levels, respectively, and gray circles indicate that the significance test has not been passed. The plus sign on the circle means a positive correlation, and the outlined box represents the region of the significant TP lakes that were analyzed in this study. The linear trends of all of the variables were removed before the correlation analysis.

motion through orographic forcing (Fig. 4d). In general, the atmospheric circulations dominated by the prevailing low pressure trough and intensified ascending motion are favorable for the formation of rainfall (Hastenrath and Greischar 1993). Liu et al. (2018) have also suggested that increased snowfall in the winter can prolong the lake ice break-up date in the following spring over southern TP through the snow-ice feedback mechanism. Therefore, these atmospheric circulation anomalies are benefited to lower the surface air temperature over the TP (Fig. 4a), which is in line with the prescribed condition of prolonged ice duration days over this region.

As indicated above, there is a significant correlation between lake ice ablation date/freeze-thaw time and the preceding boreal spring AAO. Then, a question arising here is whether the AAO can reproduce similar atmospheric circulation anomalies resembling Fig. 4. Note, however, that not all of the positive or negative AAO years are associated with prolonged or shortened ice duration years. Hence, to investigate this issue, composite analysis of atmospheric circulation anomalies for 
(a) Ts

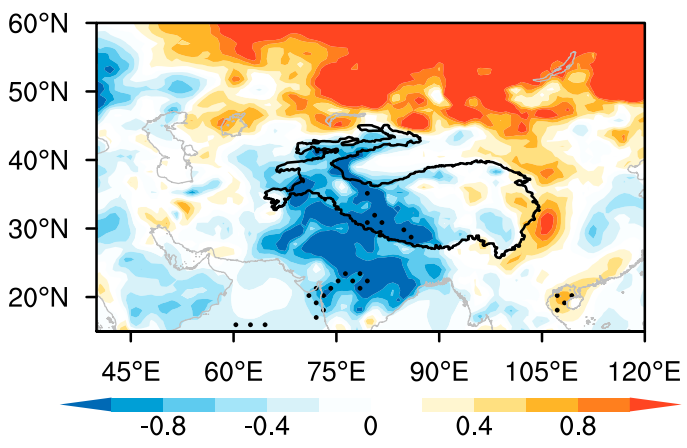

(c) WVF

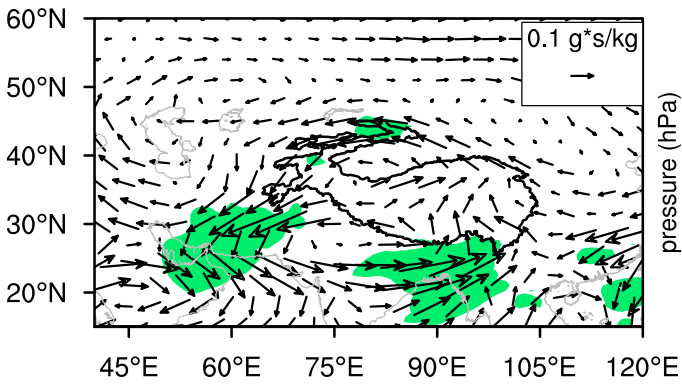

(b) Hgt500

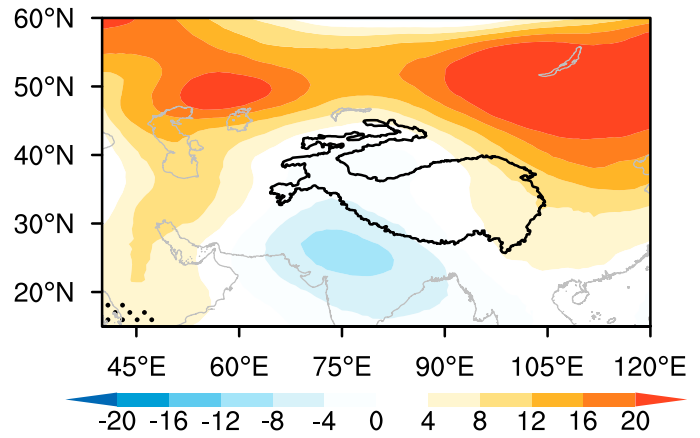

(d) Meridional circulation

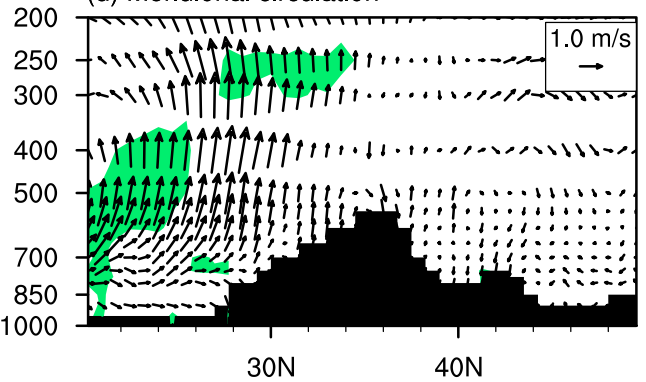

FIG. 4. Composite maps of the preceding boreal spring (February-April) (a) 2-m surface air temperature $\left({ }^{\circ} \mathrm{C}\right.$ ), (b) geopotential height field (gpm) at $500 \mathrm{hPa}$, (c) water vapor flux (WVF) transport $\left(\mathrm{g} \mathrm{s} \mathrm{kg}^{-1}\right)$ at $500 \mathrm{hPa}$, and (d) meridional circulation $\left(\mathrm{m} \mathrm{s}^{-1}\right)$ averaged over the western TP $\left(70^{\circ}-90^{\circ} \mathrm{E}\right)$ between the three longest lake ice duration events and the three shortest events. The ice duration index is calculated by the average of 41 lakes in the western TP during 2003-15. The black dots in (a) and (b) and the green shadings in (c) and (d) indicate that the anomalies are significant at the $90 \%$ confidence level from Student's $t$ test. The linear trends of all of the variables were removed before the composite analysis. The scale of the vertical wind vector has been multiplied by 500 .

three positive AAO years $(2005,2013$, and 2015) and three negative AAO years (2003, 2004, and 2007) was also conducted during 2003-15 as shown in Fig. 5 . Clearly, the anomalous negative geopotential height center can be seen over the southwestern TP, accompanied by anomalous cyclonic water vapor transport at midtropospheric circulation fields. In addition, an enhanced upward motion also occurs over the TP. As mentioned above, the prevailed low pressure trough and ascending motion across the TP are favorable to lower the surface air temperature over the western TP. It should be noted that an anomalous positive surface air temperature can be observed over a small part of the western TP. However, it disappears when the analyses are implemented using the NCEP1 reanalysis dataset. In brief, the atmospheric circulation anomalies associated with the AAO in large extent resemble that shown in Fig. 4. Therefore, the preceding boreal spring AAO might exert great influence in the variations of lake ice phenology over the TP. In the following, we will explore the possible physical mechanism of how the AAO exerts impacts on the variation of lake ice phenology over the TP.

\section{b. Impacts of the $A A O$ on the lake ice phenology}

To clearly address the issue raised above, we first show the spatial pattern of atmospheric circulation anomalies related to the AAO. Figure 6 presents the regression patterns of the geopotential height anomalies at $500 \mathrm{hPa}$ and surface wind fields with respect to the preceding spring AAO index. Obviously, the Rossby wave propagation determines the global teleconnection pattern. During the positive phase of AAO, the two branches of wave train pathway emanating from the South Pacific converge over southern Argentina and then propagate northward to the subtropical South Atlantic, and finally travel poleward through refraction over the subtropical westerlies. The tripole pattern of circulation anomalies induced by the northward wave propagation over the South Atlantic is characterized by the negative geopotential height anomalies occurring in subpolar and subtropical regions, and positive geopotential height anomalies appearing in midlatitudes (Fig. 6a). The reason why the tripole patterns of circulation anomalies do not occur over the South Pacific and Indian Oceans could be because the Rossby wave propagation is largely 
(a) Ts

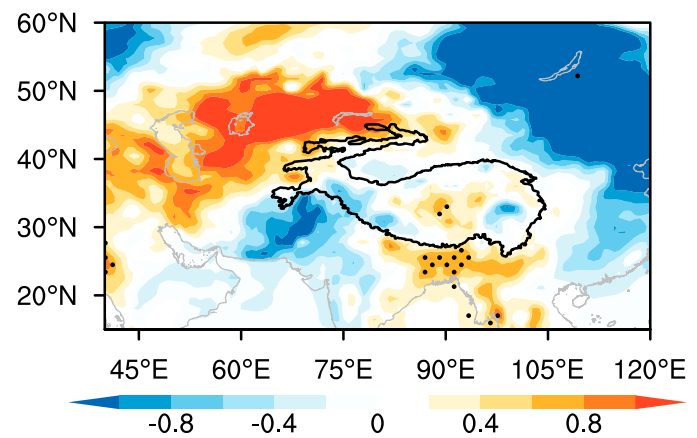

(c) WVF

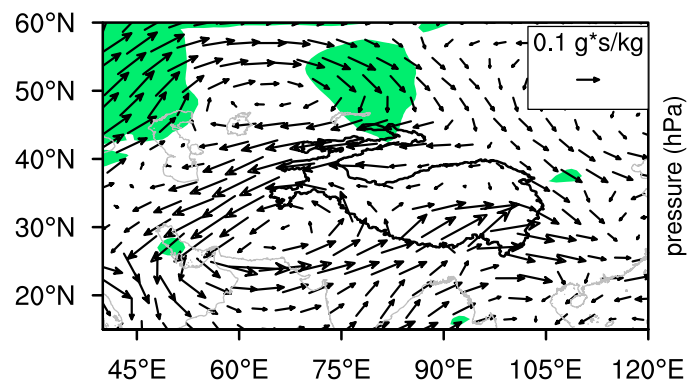

(b) Hgt500

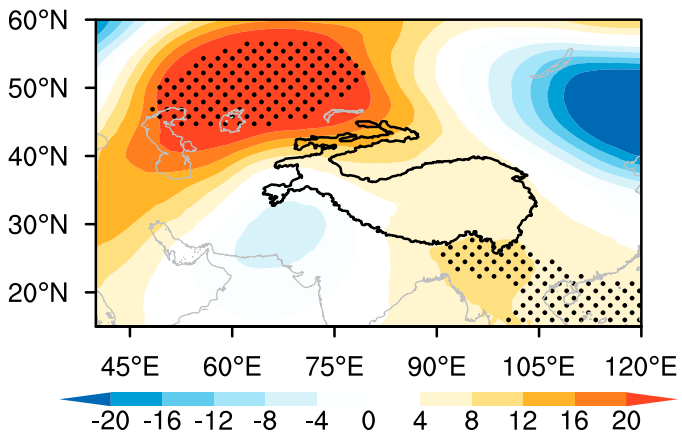

(d) Meridional circulation

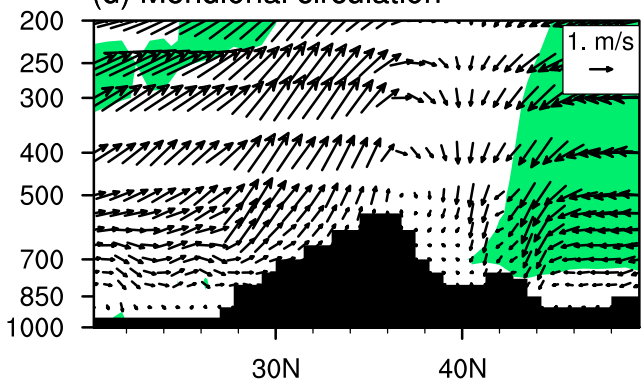

FIG. 5. As in Fig. 4, but for the composite difference between the three strongest AAO years and the three weakest AAO years in the preceding boreal spring for the same period as Fig. 4.

related to the role of the westerly jet waveguide. According to Fig. S2 of the online supplemental material, it is clear to see that there is enhanced westerly jet associated with the AAO over the subtropical regions of the eastern South Pacific and South Atlantic, whereas there is no similar phenomenon over the south Indian Ocean. The westerly jet waveguide over the tropical South Pacific stimulates the northward wave train to propagate eastward to the South Atlantic and then travel northward to the subtropical regions, and thus generates the negative geopotential height anomalies over the subtropical region (Fig. 6a). Simultaneously, along with the poleward wave train generating the negative geopotential height anomalies over the midlatitudes, there is no apparent tripole pattern of circulation anomalies over the South Pacific. As for the Indian Ocean, the main cause is that the intensity of wave activity propagation is very weak over the south Indian Ocean after the Rossby wave train propagates southward through refraction over the subtropical South Atlantic. In addition to the upper-air circulation anomalies, a similar tripole pattern can also be seen at low levels, accompanied by significant negative SLP anomalies in the subtropical and subpolar regions and positive SLP anomalies in midlatitudes (Fig. 6b). The atmospheric circulation patterns related to the AAO exhibit a significant barotropic structure that exerts impacts on the near-surface wind anomalies. It is found that the enhanced westerly wind prevails over the subpolar region, and intensive southerly wind occupies along the east coast of South America in the subtropical region while weakened easterly wind occurs over the tropical region. Previous studies have suggested that strong surface wind anomalies associated with the AAO can exert remarkable influences in the ocean surface temperature through ocean surface current and sea-air interaction (e.g., Wu et al. 2015). In addition, earlier studies have also indicated that the SST can serve as strong heat memory capability and increase the persistence of the atmosphere signal (e.g., Sen Gupta and England 2007). Hence, the role of SST anomalies in bridging the AAO and remote climate will be highlighted in the following analysis.

In general, the SST anomalies are determined by the sea surface heat budget and the marine dynamic process. Previous studies have highlighted that the mixed layer anomalies and the entrainment process below the mixed layer play an important role in the development of the dipole SST variability (e.g., Morioka et al. 2011). In addition, the important role of air-sea interaction should not be overlooked. Then, to further illuminate the impact of the AAO in generating the SST anomalies, we have investigated the ocean horizontal heat advection (Ekman heat flux), net radiation flux, and turbulent heat flux. In this study, the Ekman heat flux 


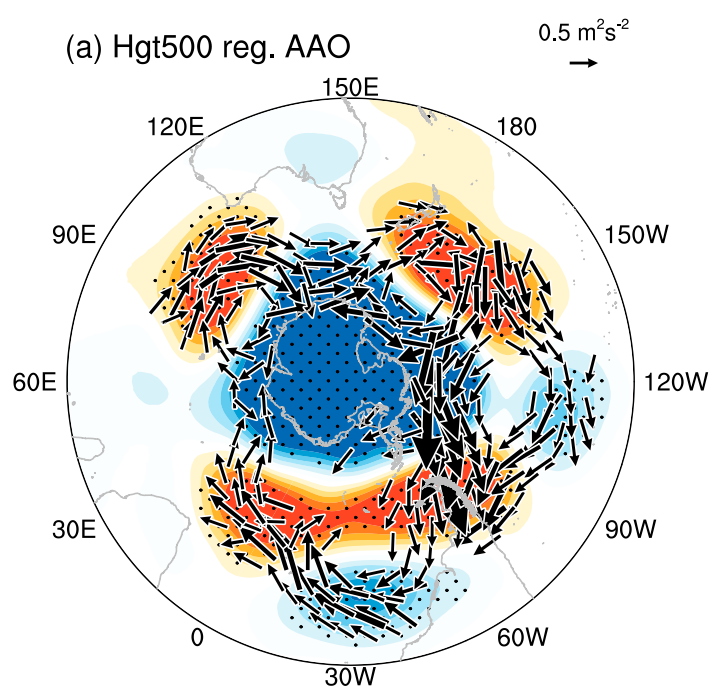
$-20-16 \quad-12 \quad-8 \quad-4$
$\begin{array}{lllll}4 & 8 & 12 & 16 & 20\end{array}$

(b) Surface wind (climatology)

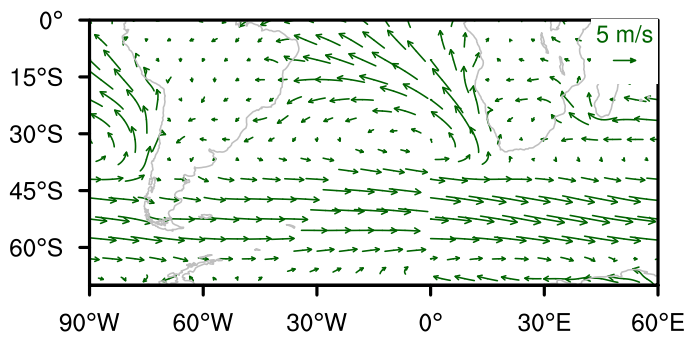

(c) Surface wind reg. AAO

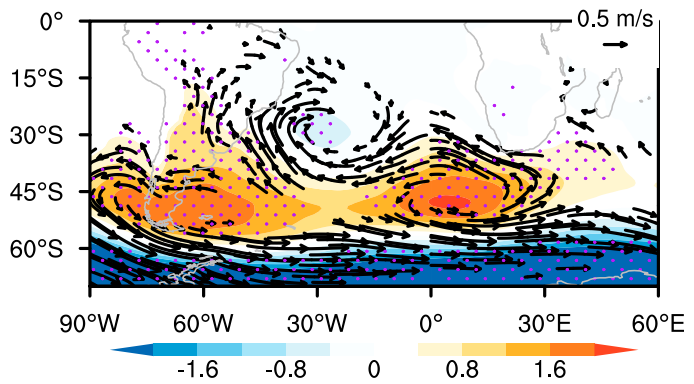

FIG. 6. Regression maps of the preceding boreal spring (a) geopotential height fields and wave activity flux (vectors; $\mathrm{m}^{2} \mathrm{~s}^{-2}$ ) at $500 \mathrm{hPa}$ and (c) 10-m wind field (black vector; $\mathrm{m} \mathrm{s}^{-1}$ ), along with SLP anomalies (color shading; $\mathrm{hPa}$ ) in the Southern Hemisphere with regard to the AAO index during 1979-2015. (b) The climatological 10-m wind (green vectors; $\mathrm{m} \mathrm{s}^{-1}$ ). The linear trends of all of the variables were removed before the regression analysis. The black dots in (a) and purple dots in (c) indicate significant regression at $90 \%$ confidence level with the Student's $t$ test.

in the upper ocean was calculated from wind stress and SST fields. As shown in Fig. 7, the total heat flux presents a tripole meridional pattern with increased heat flux in the subpolar and tropic region and decrease in midlatitudes that related to the AAO. This spatial pattern of total heat flux is mainly contributed by two components, radiation flux and latent heat flux, which show very similar anomalies. Previous studies have noted that the anomalous net radiation flux over the ocean may depend on clouds related to the AAO (Hall and Visbeck 2002; Verdy et al. 2006). The change in latent heat flux is mainly attributed to the anomalous wind velocity related to the AAO. As indicated by Fig. 6, the prevailed westerly wind anomalies induced by the AAO can weaken the climatological easterly wind and then reduce the latent heat flux. However, the Ekman heat transport shows an inconsistent pattern with total heat flux, with an enhanced horizontal heat advection over western Atlantic and reduced heat transport over the central Atlantic. Briefly, the intensity of the tripole net heat flux pattern is largely dominated by radiation heat flux and turbulent heat flux, but with a relatively weak contribution from the Ekman heat transport.

Figure 8 shows the regression maps of SST anomalies with regard to the simultaneously AAO index during 1979-2015. It is clear to see that there is a meridional tripole pattern with anomalous positive SST center in tropical Atlantic and subpolar region and negative SST center in the midlatitude region, which corresponds well to the distribution pattern of total heat flux. This spatial 
(a) Ekman heat flux

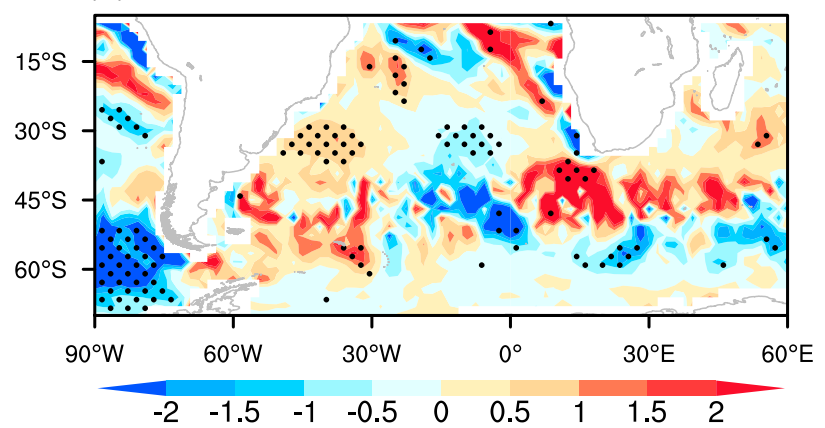

(c) Latent heat flux

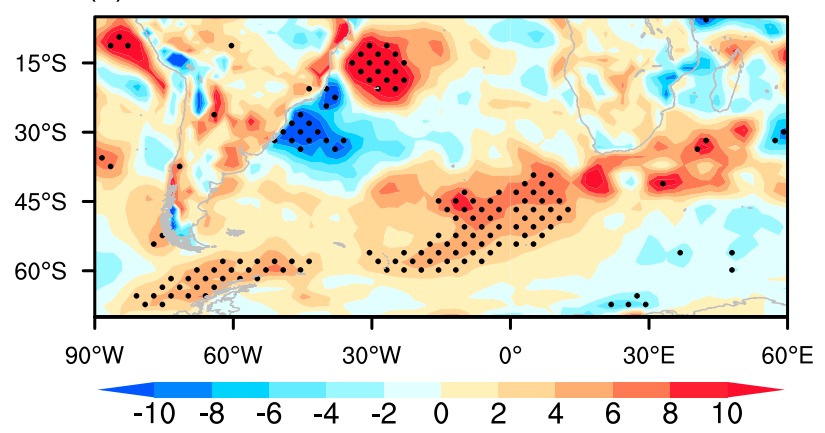

(b) Radiation flux

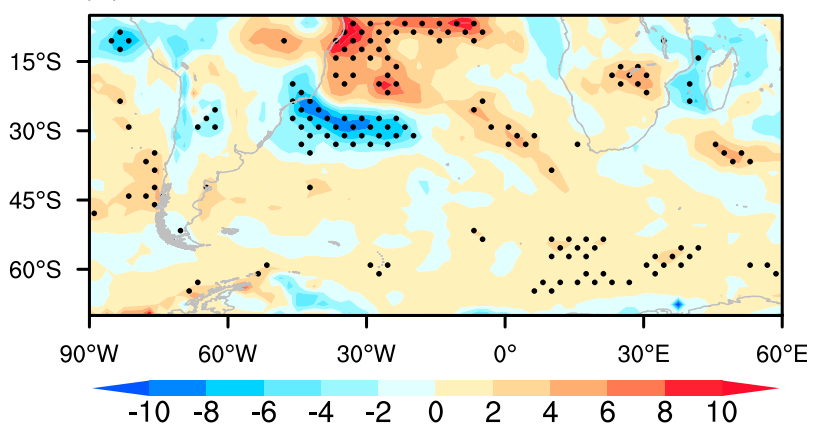

(d) Sensible heat flux

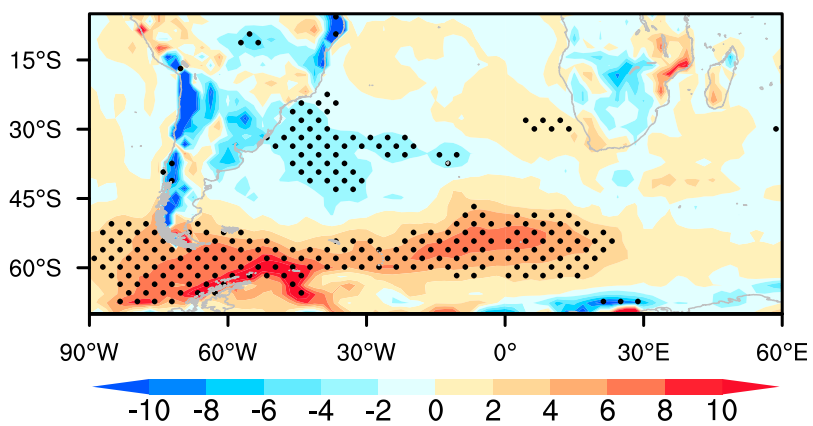

(e) Sum heat flux

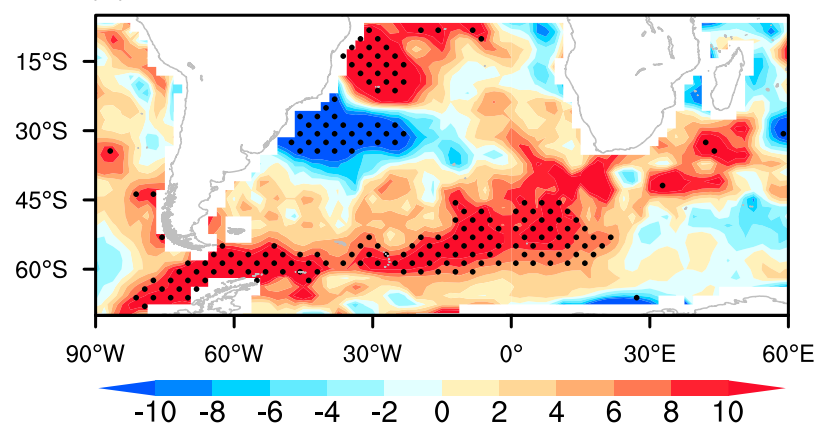

FIG. 7. Regression maps of (a) Ekman heat flux, (b) net radiation flux, (c) latent heat flux, (d) sensible heat flux, and (e) sum net heat flux $\left(\mathrm{W} \mathrm{m}^{-2}\right)$ against the boreal spring AAO index during 1979-2015. Positive values indicate that radiation flux and turbulent heat flux (multiplied by -1) are downward, which contributes to positive SST anomalies. Negative values indicate that radiation flux and turbulent heat flux (multiplied by -1) are upward, which contributes to negative SST anomalies. The linear trends of all of the variables were removed before the regression analysis. The black dots indicate significant regression at $90 \%$ confidence level with the Student's $t$ test.

pattern of SST anomaly over the South Atlantic is also robust when the ENSO signal removed. To quantitatively depict such AAO-related SST anomalies variability and possible remote impact on the Northern Hemisphere climate, the tropical Atlantic SST index (TAS) is obtained by projecting the regressed SST fields in the tropical Atlantic $\left(40^{\circ} \mathrm{W}-5^{\circ} \mathrm{E}, 15^{\circ} \mathrm{S}-5^{\circ} \mathrm{N}\right)$ onto the standardized SST pattern in the same area (e.g., Dou and Wu 2018). Figure $8 \mathrm{c}$ shows the temporal series of the preceding boreal spring AAO index and the calculated TAS and a strong interannual variability can be observed for these two indices. The correlation coefficient between the AAO and TAS reaches 0.42 , passing the significant test at the $95 \%$ confidence level, which implies that the AAO can exert great influences in generating the tropical Atlantic SST anomalies. Previous studies have highlighted the important role of tropical ocean SST anomalies in bridging interhemispheric climate (Dou and Wu 2018; Kucharski et al. 2007; Kucharski et al. 2008; Kucharski et al. 2009). Some studies have pointed out that the tropical SST anomalies over the Atlantic can induce the extratropical portion of the North Atlantic SST tripole (NAT) through forcing a barotropic teleconnection into the extratropics (e.g., Okumura et al. 2001). Evidently, 
(a) AAO reg. SST

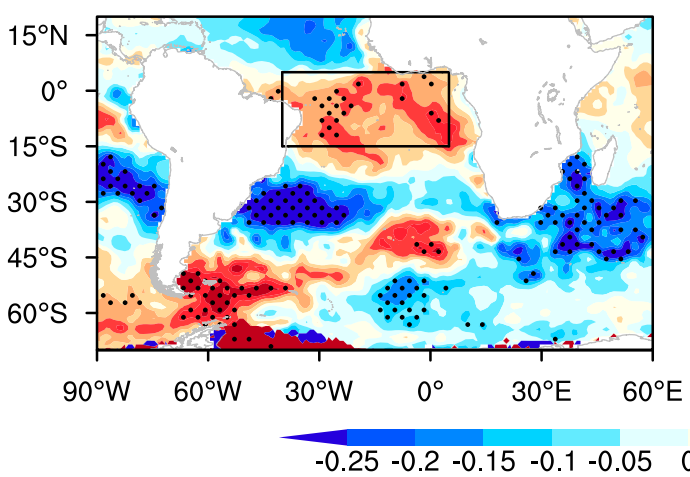

(b) ENSO removed

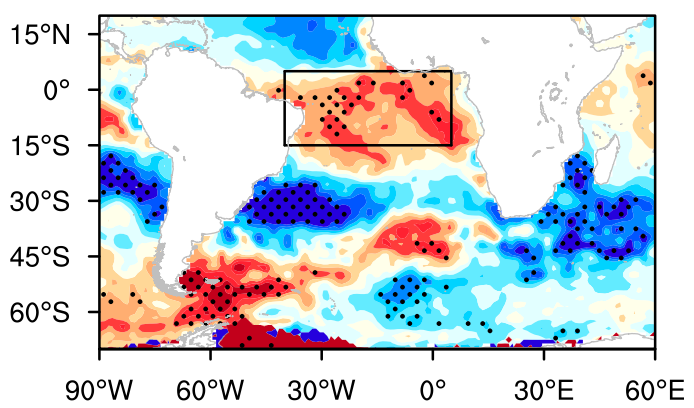

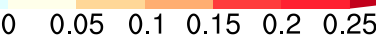

(c)

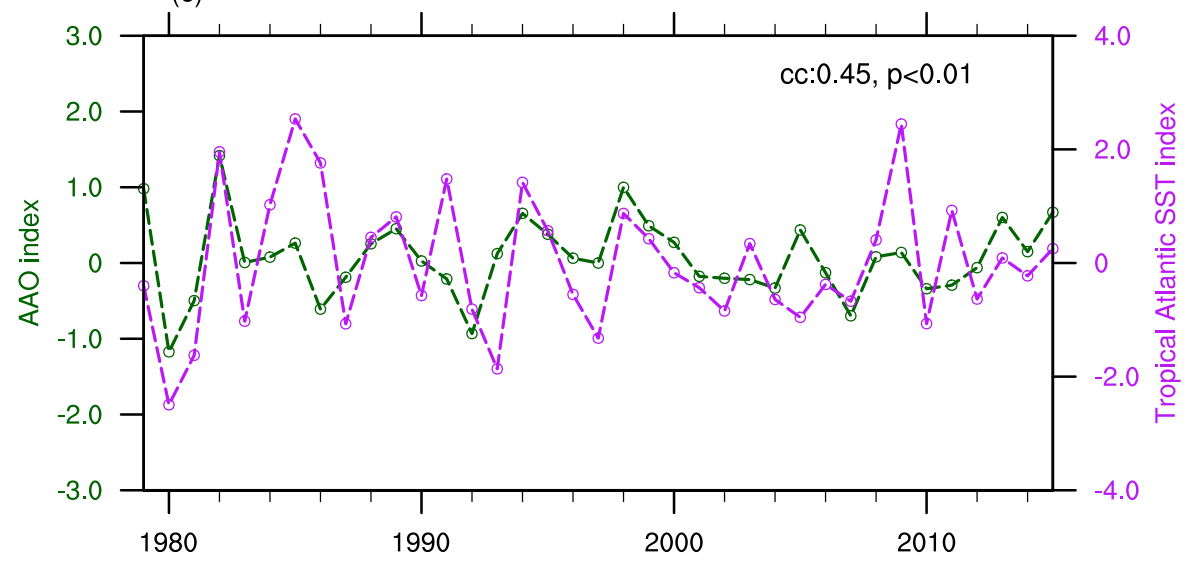

FIG. 8. Regression maps of the preceding boreal spring (a) SST $\left({ }^{\circ} \mathrm{C}\right)$ against the AAO index during 1979-2015, and (b) for the partial regression patterns with the winter ENSO signal removed. (c) The temporal series of the AAO index and TAS obtained by projecting the regressed SST fields in the tropical Atlantic $\left(40^{\circ} \mathrm{W}-5^{\circ} \mathrm{E}, 15^{\circ} \mathrm{S}-5^{\circ} \mathrm{N}\right)$ onto the normalized SST pattern in the same area. The linear trends of all of the variables were removed before the correlation analysis. The black dots indicate significant regression at $90 \%$ confidence level with the Student's $t$ test.

the wind-induced sea surface evaporation favors enlarging the cross-equatorial SST gradient through organizing off-equatorial Atlantic SST anomalies, which results in the shift of the Atlantic intertropical convergence zone (ITCZ) and finally affect the NAO (e.g., Xie and Carton 2004). Although some studies have identified the important role of tropical SST anomalies in the interaction between interhemispheric climate, the mechanisms for spring AAO-induced tropical South Atlantic SST anomalies affecting the Northern Hemisphere climate remain unclear. To investigate this issue, the regression analysis of averaged meridional circulation around $60^{\circ} \mathrm{W}-0^{\circ}$ with regard to the simultaneous TAS index was conducted. As indicated by Fig. 9a, it is clear to see that an anomalous enhanced downward motion dominates subtropical regions, which can strengthen the subsidence here. As a result, there is significant ascending motion over the tropical Atlantic, while the enhanced descending motion dominates over the subtropical regions in the Northern Hemisphere, which is favorable to strengthen the Azores high (Fig. 9b). Subsequently, the intensive anticyclone can exert remarkable influences on the surface prevailing wind fields. Obviously, the prevailing westerlies over the midlatitudes regions have intensified, while the prevailing winds off the eastern United States have abated due to anomalous easterly weakening the climatological westerly around the latitude of $30^{\circ} \mathrm{N}$. The wind response is in support of the wind-evaporation-SST (WES) feedback (Chang et al. 1997; Xie and Tanimoto 1998), which corresponds well to the NAT pattern (Fig. 9c). Hence, the footprint of the preceding boreal spring AAO imprinting the Atlantic Ocean is the vital process in linking the AAO to the Northern Hemisphere climate. To further quantify the relationships between the tropical Atlantic SST variations and the preceding spring NAT pattern, a new index is retrieved by projecting the regressed SST fields in the North Atlantic Ocean $\left(5^{\circ}-60^{\circ} \mathrm{N}, 10^{\circ}-70^{\circ} \mathrm{W}\right)$ onto the standardized SST pattern in the same area (Fig. 10). Clearly, the NAT shows a strong intimate correlation of 0.54 to the 
(a) Meridional circulation

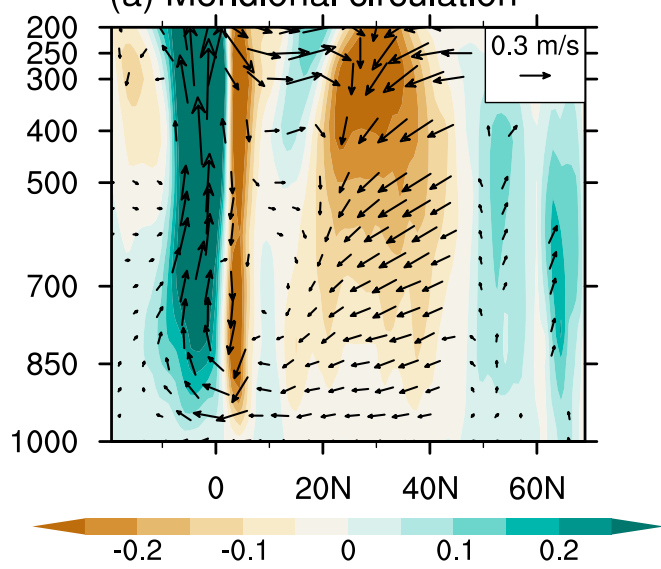

(c) SLP\&SW

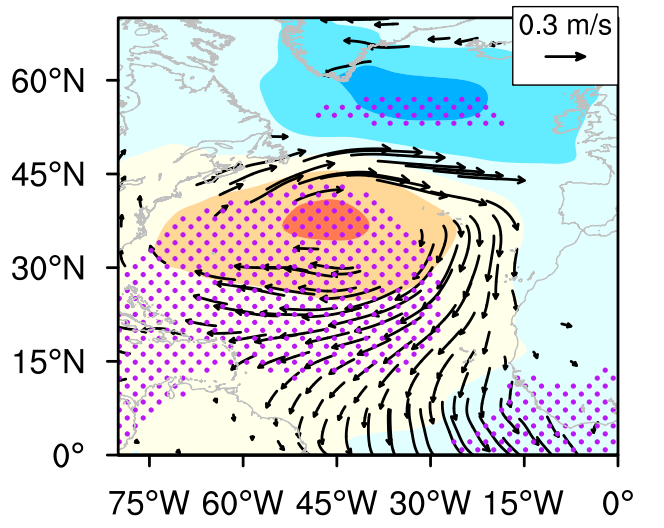

(b) Surface wind (climatology)

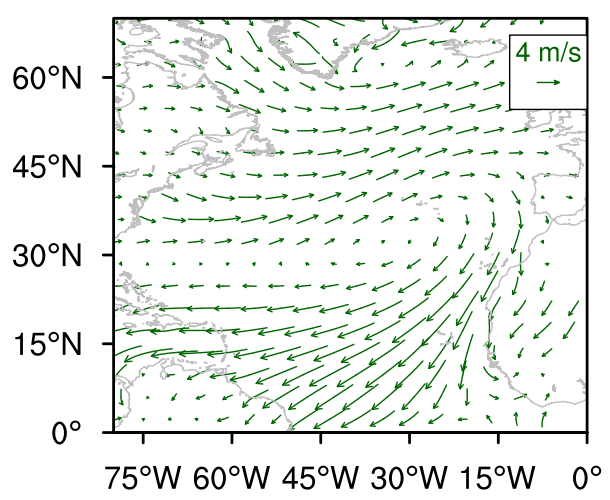

(d) SST

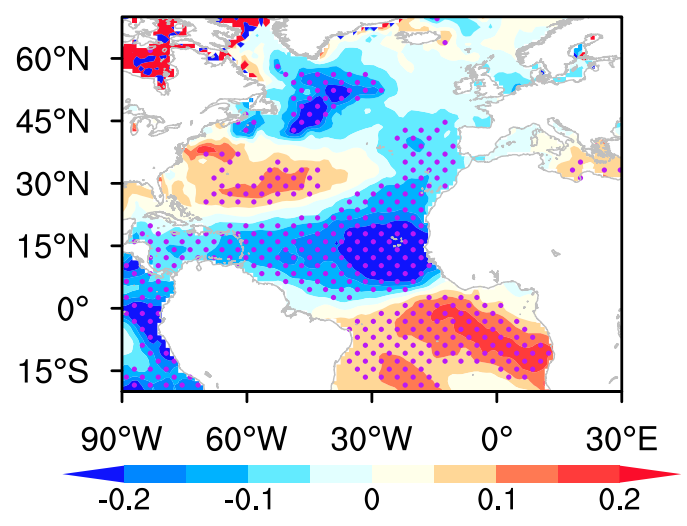

FIG. 9. Regression maps of the preceding boreal spring (a) meridional circulation (vectors, averaged around $60^{\circ} \mathrm{W}-0^{\circ} ; \mathrm{m} \mathrm{s}^{-1}$ ) and climatological vertical velocity (multiplied by 500 , color shading; $\mathrm{m} \mathrm{s}^{-1}$ ), (c) 10 -m wind field (black vectors; $\mathrm{m} \mathrm{s}^{-1}$ ) and SLP anomalies (color shading; $\mathrm{hPa}$ ), and (d) sea surface temperature $\left({ }^{\circ} \mathrm{C}\right.$ ) against the TAS index during 1979-2015. (b) The climatological 10-m wind (green vectors; $\mathrm{m} \mathrm{s}^{-1}$ ). The linear trends of all of the variables were removed before the correlation analysis. The purple dots in (c) and (d) indicate significant regression at $90 \%$ confidence level with the Student's $t$ test.

TAS index, passing the significance test at the $99.9 \%$ confidence level, which indicates that there is an intimate correlation between the TAS and the spring NAT pattern.

Previous studies have demonstrated that the North Atlantic SST can exert remarkable influences on the climate over Eurasia (Chen and Wu 2017; Cui et al. 2015; Li et al. 2018; Wu et al. 2011). For example, $\mathrm{Li}$ et al. (2018) have revealed that the North Atlantic SST anomalies can stimulate a North Atlantic-western Russia-western TP-southwestern China teleconnection wave train that exerts impacts on the atmospheric circulation anomalies over southern Asia. Some studies have also highlighted the important role of the NAT on the East Asian climates (e.g., Zuo et al. 2013).
Hence, the North Atlantic SST anomalies may be the critical role in bridging the preceding spring AAO and the TP climate. In the following, the possible linkage between North Atlantic SST anomalies and regional atmospheric circulation anomalies over the TP will be explored.

Figure 11 shows the regression patterns of atmospheric circulation anomalies with regard to the NAT index during 1979-2015. Obviously, an anomalous cyclonic circulation dominates over the TP, accompanied by the anomalous enhancement of water vapor transport over this region. Furthermore, there is a strengthened updraft occurring over the TP, which is attributed to the enhanced southwesterly wind over the south flank of TP and topographic lifting. These atmospheric 


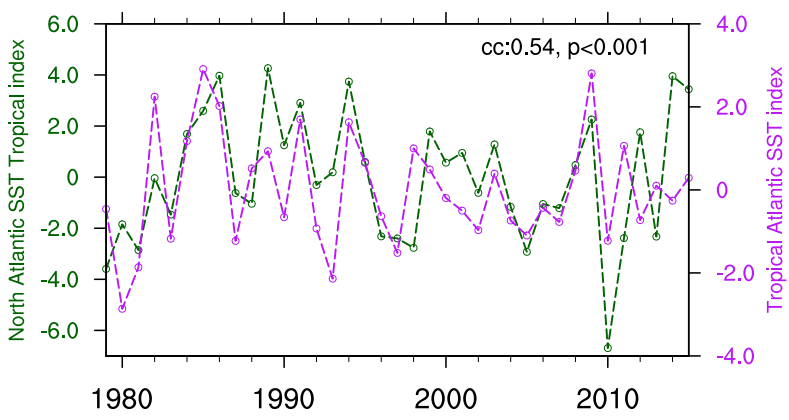

FIG. 10. The temporal series of the detrended TAS index (purple) and NAT index (green) obtained by projecting the regressed SST fields in the North Atlantic $\left(5^{\circ}-60^{\circ} \mathrm{N}, 10^{\circ}-70^{\circ} \mathrm{W}\right)$ onto the normalized SST pattern in the same area.

circulation anomalies over the TP provides a favorable environment for snowfall and then lower the surface temperature, which corresponds well to the negative surface air temperature anomalies related to the NAT pattern in Fig. 11a. Subsequently, the negative temperature anomalies in preceding spring can postpone the lake ice melting date and prolong the lake ice duration. Thus, the Atlantic SST anomalies associated with preceding spring AAO can exert a remote impact on the regional atmospheric circulation anomalies over the TP, which resembles the atmospheric circulation pattern related to the prolonging freeze-thaw events.

As mentioned above, there is an intimate relationship between Atlantic SST anomalies and variations in lake ice phenology over the TP. A question arising here is how the Atlantic SST anomalies are connected to the change in atmospheric circulation over the TP. To investigate the remote impact of atmospheric teleconnection on the regional atmospheric circulation over the $\mathrm{TP}$, the stationary wave activity flux associated with the NAT index (Fig. 12) was calculated based on the method proposed by Takaya and Nakamura (2001). Clearly, there are two significant wave activity flux propagation pathways over Eurasia and subtropical Atlantic, which can be traced back to the warm core in the North Atlantic. The northward wave train propagates from North Atlantic to Greenland and then eastward to western Europe, the

\section{(a) Ts reg. NAT}

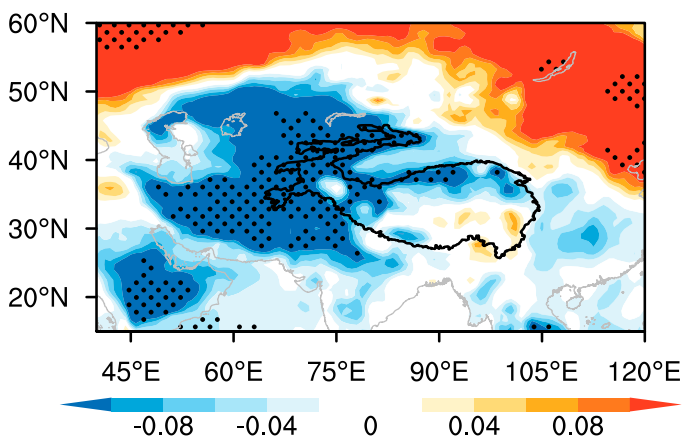

(c) WVF reg. NAT

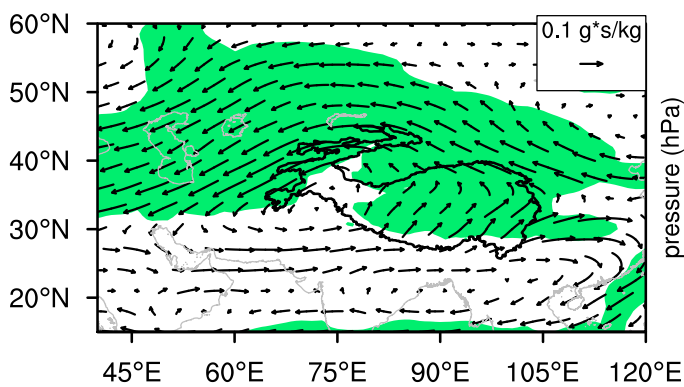

(b) Hgt reg. NAT

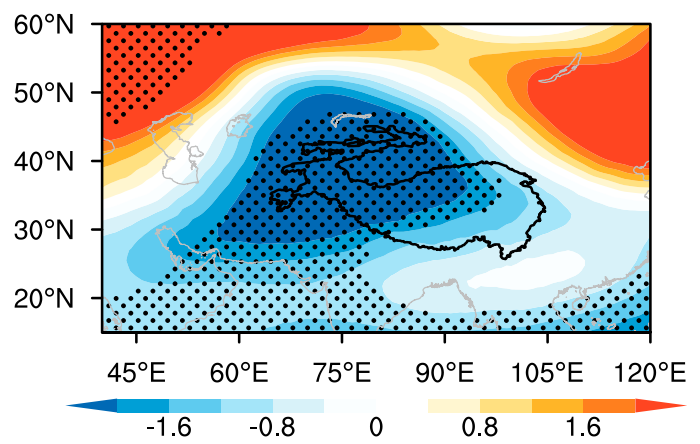

(d) Meridional circulation reg. NAT

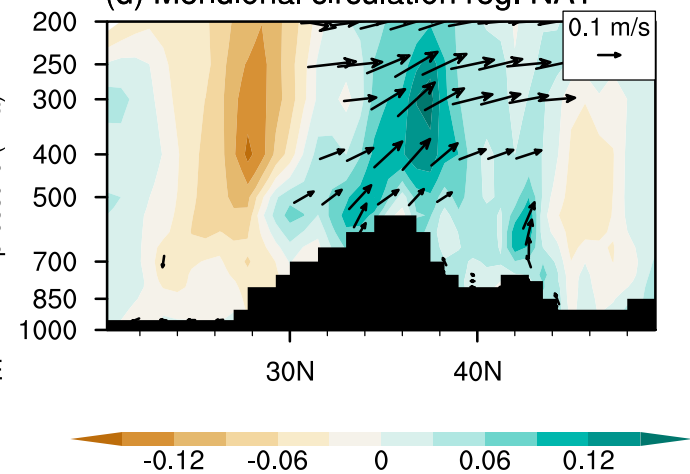

FIG. 11. Regression maps of the preceding boreal spring (a) 2-m surface air temperature $\left({ }^{\circ} \mathrm{C}\right)$, (b) geopotential height field (gpm) at $500 \mathrm{hPa}$, (c) WVF transport $\left(\mathrm{g} \mathrm{s}^{-1} \mathrm{hPa}^{-1} \mathrm{~cm}^{-1}\right)$ at $500 \mathrm{hPa}$, and (d) meridional circulation $\left(\mathrm{m} \mathrm{s}^{-1}\right)$ averaged over the western TP $\left(70^{\circ}-90^{\circ} \mathrm{E}\right)$ against the NTA index. The linear trends of all of the variables were removed before the correlation analysis. The black dots in (a) and (b) and the green shadings in (c) and (d) indicate that the anomalies are significant at the $90 \%$ confidence level from the Student's $t$ test. The scale of the vertical wind vector has been multiplied by 500 . 
(a) WAF reg. NAT

$500 \mathrm{hPa}$

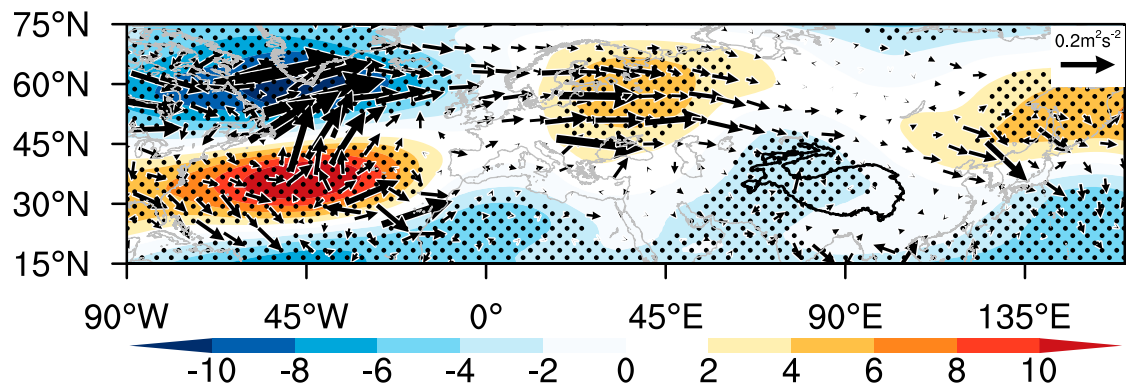

(b) WAF reg. NAT

$300 \mathrm{hPa}$

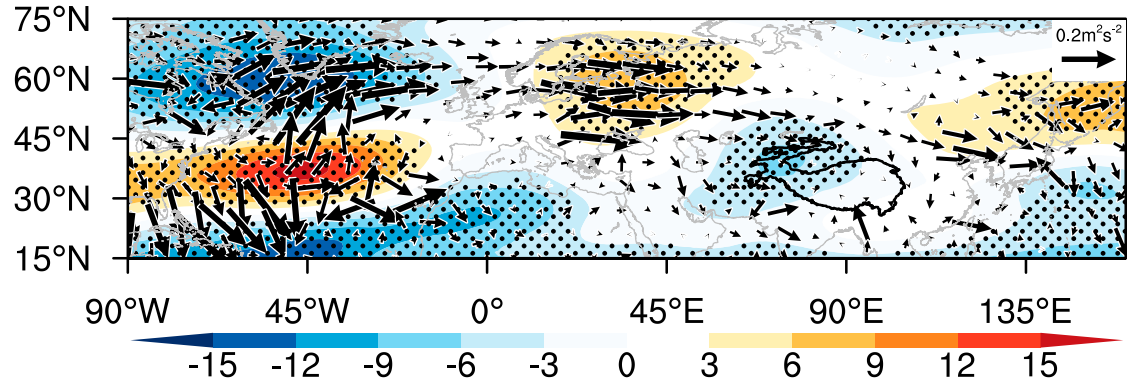

(c) WAF reg. NAT

$200 \mathrm{hPa}$

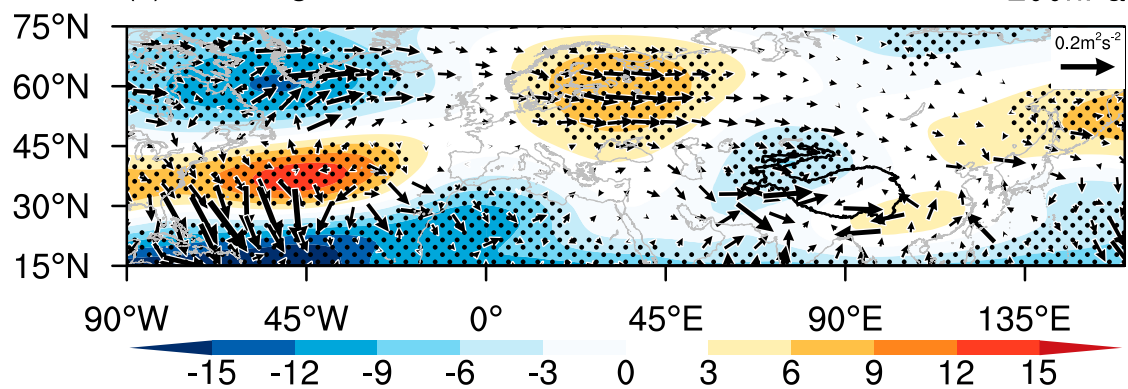

FIG. 12. Regression maps of the preceding boreal spring (a) 500-, (b) 300-, and (c) 200-hPa wave activity flux (vectors; $\mathrm{m}^{2} \mathrm{~s}^{-2}$ ) and geostrophic streamfunction (shading; $10^{5} \mathrm{~m}^{2} \mathrm{~s}^{-1}$ ) anomalies against the NTA index. The linear trends of all of the variables were removed before the regression analysis. The black dots indicate significant regression at $90 \%$ confidence level with the Student's $t$ test.

TP, and finally to northeastern Asia while the south branch wave train emanates from the North Atlantic warm core southward to the subtropical region. Subsequently, the Rossby wave train along the European continent can result in negative geopotential height anomalies over the TP. To some extent, the above analysis implies that the North Atlantic SST anomalies can exert remarkable influences on the atmospheric circulation anomalies through stimulating stationary Rossby wave train and then modulate the changes in lake ice phenology over the TP.

In addition, we also employed similar analyses to illustrate the remote impact of the preceding boreal spring AAO on the western TP on the basis of the two kinds of the reanalysis datasets and analysis period (Figs. S3-S16 of the online supplemental material), and the results indicated that the conclusions are still robust.

\section{Discussion and conclusions}

Lake ice, as an important component of the TP cryosphere, has great implications for understanding the regional climate change and climate monitoring (Chakraborty et al. 2002; Duan et al. 2012; Rangwala et al. 2009; Shaman and Tziperman 2005). However, due to the sparse in situ monitoring of lake ice phenology and difficult accessibility to the TP, the satellite 
remote sensing monitoring has been an effective measure of inversion of lake ice phenology, and provides a credible validation to evaluate regional climate change (Cai et al. 2017; Du et al. 2017; Qiu et al. 2017a). Although some studies have investigated the variations in lake ice phenology in response to global warming at some parts of the Northern Hemisphere, relatively few studies contribute to the physical mechanism of how climate change influences the lake ice phenology over the TP. In this study, we first investigate the statistical characteristics of lake ice phenology over the TP during 2002-15. The results show that the average ice formation date over the TP lakes generally occurs on 14 November and ice break-up date on 9 May, resulting in 180 days of ice cover. In addition, it is found that the changes in lake ice duration vary from their locations across the TP mainly due to the inconsistent changes in freezing date and ablation time. Further statistical results reveal that there is a significant correlation between the preceding boreal spring AAO and break-up dates/ice duration days over the TP.

Furthermore, the possible impact of the AAO on the variations in lake ice phenology over the TP was illustrated (Fig. 13). During the positive phase of AAO, the preceding spring AAO-induced atmospheric circulation anomalies are favorable to generate tropical South Atlantic SST anomalies through air-sea interaction. Then the tropical SST anomalies strengthen the subsidence branch of Hadley circulation that projects into the Azores high and further induce the extratropical portion of the NAT. Further analysis shows that North Atlantic SST anomalies can stimulate a stationary Rossby wave train, which can exert impacts on the regional atmospheric circulation anomalies over the TP. Consequently, the anomalous cyclonic circulation and strengthened updraft over the TP are favorable to the increased occurring probability of snowfall events and then lower the surface air temperature according to the snow-albedo feedback mechanism, and finally result in the prolonged lake ice duration.

In addition to the important role of tropical Atlantic SST in bridging the AAO and Northern Hemisphere climate, previous studies have also highlighted the role of the atmospheric bridge over the Indian Ocean and Pacific in linking the interhemispheric climates (Prabhu et al. 2016; Sun 2010; Sun et al. 2009, 2010; Wu et al. 2015). For example, Sun et al. (2009) have demonstrated that boreal spring AAO-induced atmospheric circulation anomalies over the south Indian Ocean and South Pacific are closely related to the variations of Yangtze River valley summer rainfall. Dou and Wu (2018) proposed that interannual variation of the TP climate in boreal summer may originate from the May SAM through

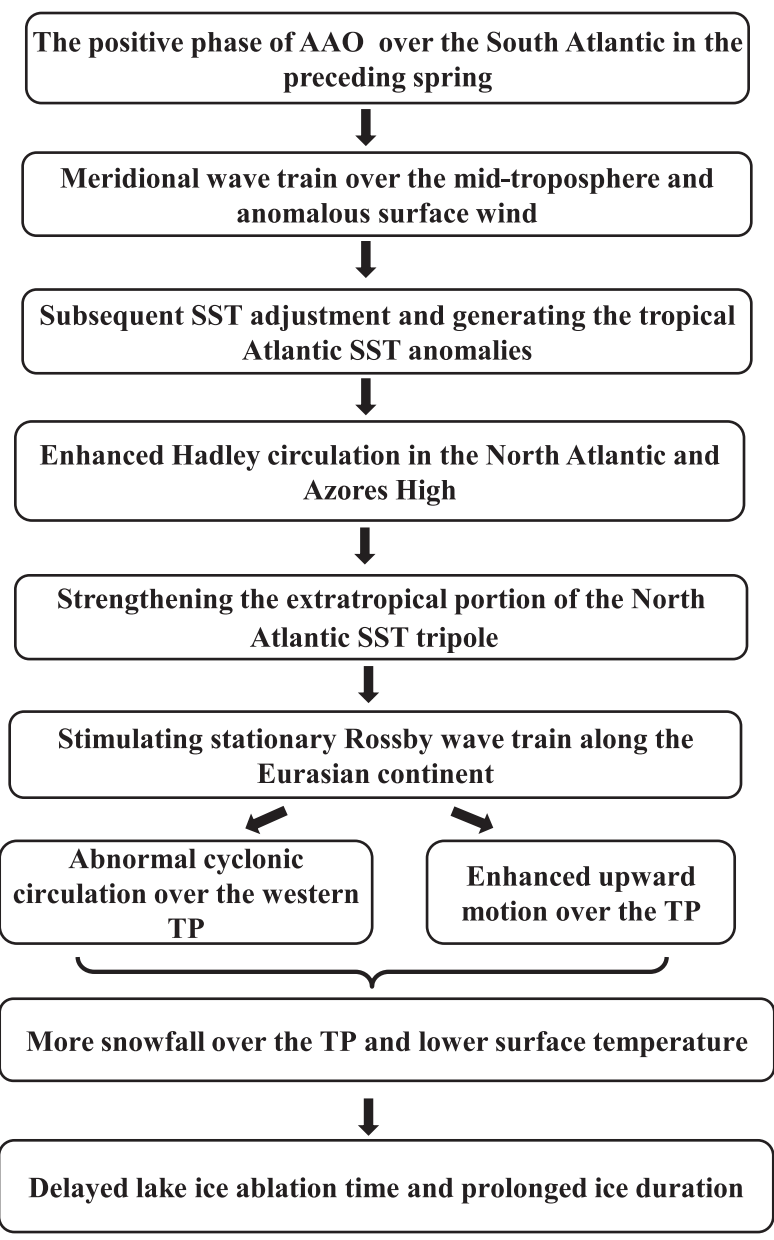

FIG. 13. A schematic diagram of the possible physical processes by which the preceding boreal spring AAO affects the variations in lake ice ablation time/ice duration over the TP.

the ocean bridge and atmosphere bridge in the Indian Ocean. The increasing evidence gives us a better understanding that the AAO may be considered as a potential predictor for the TP climate. However, there are still some outstanding issues that need further investigation. For example, the lack of a dataset of lake ice phenology over the TP makes weak evidence for the physical mechanism of the lake ice responding to climate change. It is a challenging topic to depict the changes in TP climate mainly due to the climate shocks in recent years, such as dramatic decline in Arctic sea ice concentration, a switch to a negative phase of Pacific decadal oscillation, the increased heat uptake in deeper ocean, and so on (e.g., Balmaseda et al. 2013; Trenberth and Fasullo 2013; Vihma 2014; Wang et al. 2015). Hence, there is an urgent need for further research to explore the changes in the lake ice phenology over the TP in response to climate change using long-term datasets of climate and limnology in the future. 
Acknowledgments. This research was jointly supported by the Strategic Priority Research Program of the Chinese Academy of Sciences (Grant XDA19070201), the National Key Research and Development Program of China (Grant 2016YFA0602701), and the open program of Joint Laboratory of Climate and Environment Change, Chengdu University of Information Technology (Grant JLCEC201801).

\section{REFERENCES}

Balmaseda, M., K. Trenberth, and E. Källén, 2013: Distinctive climate signals in reanalysis of global ocean heat content. Geophys. Res. Lett., 40, 1754-1759, https://doi.org/10.1002/ grl.50382.

Benson, B., and Coauthors, 2012: Extreme events, trends, and variability in Northern Hemisphere lake-ice phenology (18552005). Climatic Change, 112, 299-323, https://doi.org/10.1007/ s10584-011-0212-8.

Cai, Y., C. Ke, and Z. Duan, 2017: Monitoring ice variations in Qinghai Lake from 1979 to 2016 using passive microwave remote sensing data. Sci. Total Environ., 607-608, 120-131, https://doi.org/10.1016/j.scitotenv.2017.07.027.

Chakraborty, A., R. Nanjundiah, and J. Srinivasan, 2002: Role of Asian and African orography in Indian summer monsoon. Geophys. Res. Lett., 29, 1989, https://doi.org/10.1029/ 2002 GL015522.

Chang, P., L. Ji, and H. Li, 1997: A decadal climate variation in the tropical Atlantic Ocean from thermodynamic air-sea interactions. Nature, 385, 516-518, https://doi.org/10.1038/385516a0.

Chen, S., and R. Wu, 2017: Interdecadal changes in the relationship between interannual variations of spring North Atlantic SST and Eurasian surface air temperature. J. Climate, 30, 37713787, https://doi.org/10.1175/JCLI-D-16-0477.1.

Cui, Y., A. Duan, Y. Liu, and G. Wu, 2015: Interannual variability of the spring atmospheric heat source over the Tibetan Plateau forced by the North Atlantic SSTA. Climate Dyn., 45, 16171634, https://doi.org/10.1007/s00382-014-2417-9.

Dee, D., and Coauthors, 2011: The ERA-Interim reanalysis: Configuration and performance of the data assimilation system. Quart. J. Roy. Meteor. Soc., 137, 553-597, https://doi.org/ 10.1002/qi.828.

Dou, J., and Z. Wu, 2018: Southern Hemisphere origins for interannual variations of snow cover over the western Tibetan Plateau in boreal summer. J. Climate, 31, 7701-7718, https:// doi.org/10.1175/JCLI-D-17-0327.1.

— - _ and Y. Zhou, 2017: Potential impact of the May Southern Hemisphere annular mode on the Indian summer monsoon rainfall. Climate Dyn., 49, 1257-1269, https://doi.org/ 10.1007/s00382-016-3380-4.

Du, J., J. Kimball, C. Duguay, Y. Kim, and J. Watts, 2017: Satellite microwave assessment of Northern Hemisphere lake ice phenology from 2002 to 2015. Cryosphere, 11, 47-63, https:// doi.org/10.5194/tc-11-47-2017.

Du, Q., H. Liu, L. Xu, Y. Liu, and L. Wang, 2018: The monsoon effect on energy and carbon exchange processes over a highland lake in the southwest of China. Atmos. Chem. Phys., 18, 15 087-15 104, https://doi.org/10.5194/acp-18-15087-2018.

Duan, A., G. Wu, Y. Liu, Y. Ma, and P. Zhao, 2012: Weather and climate effects of the Tibetan Plateau. Adv. Atmos. Sci., 29, 978-992, https://doi.org/10.1007/s00376-012-1220-y.
Gong, D., and S. Wang, 1999: Definition of Antarctic Oscillation index. Geophys. Res. Lett., 26, 459-462, https://doi.org/10.1029/ 1999GL900003.

Guo, D., J. Sun, and E. Yu, 2018: Evaluation of CORDEX regional climate models in simulating temperature and precipitation on the Tibetan Plateau. Atmos. Oceanic Sci. Lett., 11, 219-227, https://doi.org/10.1080/16742834.2018.1451725.

Hall, A., and M. Visbeck, 2002: Synchronous variability in the Southern Hemisphere atmosphere, sea ice, and ocean resulting from the annular mode. J. Climate, 15, 3043-3057, https:// doi.org/10.1175/1520-0442(2002)015<3043:SVITSH >2.0.CO;2.

Hastenrath, S., and L. Greischar, 1993: Circulation mechanisms related to northeast Brazil rainfall anomalies. J. Geophys. Res., 98, 5093-5102, https://doi.org/10.1029/92JD02646.

Hsu, H.-H., and X. Liu, 2003: Relationship between the Tibetan Plateau heating and East Asian summer monsoon rainfall. Geophys. Res. Lett., 30, 2066, https://doi.org/10.1029/2003GL017909.

Hua, W., K. Yang, and G. Fan, 2017: Uncertainty in hottest years ranking: Analysis of Tibetan Plateau surface air temperature. Atmos. Oceanic Sci. Lett., 10, 337-341, https://doi.org/10.1080/ 16742834.2017.1330646.

Kanamitsu, M., W. Ebisuzaki, J. Woollen, S.-K. Yang, J. Hnilo, M. Fiorino, and G. Potter, 2002: NCEP-DOE AMIP-II Reanalysis (R-2). Bull. Amer. Meteor. Soc., 83, 1631-1643, https:// doi.org/10.1175/BAMS-83-11-1631.

Korhonen, J., 2006: Long-term changes in lake ice cover in Finland. Hydrol. Res., 37, 347-363, https://doi.org/10.2166/nh.2006.019.

Kucharski, F., A. Bracco, J. Yoo, and F. Molteni, 2007: Lowfrequency variability of the Indian monsoon-ENSO relationship and the tropical Atlantic: The "weakening" of the 1980s and 1990s. J. Climate, 20, 4255-4266, https://doi.org/10.1175/ JCLI4254.1.

,,--- , and -2008 : Atlantic forced component of the Indian monsoon interannual variability. Geophys. Res. Lett., 35, L04706, https://doi.org/10.1029/2007GL033037.

,-- , A. Tompkins, L. Feudale, P. Ruti, and A. Dell'Aquila, 2009: A Gill-Matsuno-type mechanism explains the tropical Atlantic influence on African and Indian monsoon rainfall. Quart. J. Roy. Meteor. Soc., 135, 569-579, https://doi.org/10.1002/qj.406.

Kwok, R., and J. Comiso, 2002: Spatial patterns of variability in Antarctic surface temperature: Connections to the Southern Hemisphere annular mode and the Southern Oscillation. Geophys. Res. Lett., 29, 1705, https://doi.org/10.1029/ 2002 GL015415.

Latifovic, R., and D. Pouliot, 2007: Analysis of climate change impacts on lake ice phenology in Canada using the historical satellite data record. Remote Sens. Environ., 106, 492-507, https://doi.org/10.1016/j.rse.2006.09.015.

Li, G., J. Chen, X. Wang, X. Luo, D. Yang, W. Zhou, Y. Tan, and H. Yan, 2018: Remote impact of North Atlantic sea surface temperature on rainfall in southwestern China during boreal spring. Climate Dyn., 50, 541-553, https://doi.org/10.1007/ s00382-017-3625-x

Liu, G., R. Wu, and Y. Zhang, 2014: Persistence of snow cover anomalies over the Tibetan Plateau and the implications for forecasting summer precipitation over the meiyu-baiu region. Atmos. Oceanic Sci. Lett., 7, 115-119, https://doi.org/10.1080/ 16742834.2014.11447145.

Liu, Y., H. Chen, H. Wang, and Y. Qiu, 2018: The impact of the NAO on the delayed break-up date of lake ice over the southern Tibetan Plateau. J. Climate, 31, 9073-9086, https://doi.org/ 10.1175/JCLI-D-18-0197.1. 
,,--- J. Sun, H. Li, and Y. Qiu, 2019a: Modulation of the Kara sea ice variation on the ice freeze-up time in Lake Qinghai. J. Climate, 32, 2553-2569, https://doi.org/10.1175/ JCLI-D-18-0636.1.

, G. Zhang, J. Sun, and H. Wang, 2019b: The advanced South Asian monsoon onset accelerates lake expansion over the Tibetan Plateau. Sci. Bull., 64, 1486-1489, https://doi.org/ 10.1016/j.scib.2019.08.011.

Livingstone, D., 1997: Break-up dates of alpine lakes as proxy data for local and regional mean surface air temperatures. Climatic Change, 37, 407-439, https://doi.org/10.1023/A:1005371925924.

Mo, K., 2000: Relationships between low-frequency variability in the Southern Hemisphere and sea surface temperature anomalies. J. Climate, 13, 3599-3610, https://doi.org/10.1175/ 1520-0442(2000)013<3599:RBLFVI > 2.0.CO;2.

Morioka, Y., T. Tozuka, and T. Yamagata, 2011: On the growth and decay of the subtropical dipole mode in the South Atlantic. J. Climate, 24, 5538-5554, https://doi.org/10.1175/ 2011JCLI4010.1.

Okumura, Y., S.-P. Xie, A. Numaguti, and Y. Tanimoto, 2001: Tropical Atlantic air-sea interaction and its influence on the NAO. Geophys. Res. Lett., 28, 1507-1510, https://doi.org/ 10.1029/2000GL012565.

Prabhu, A., R. Kripalani, B. Preethi, and G. Pandithurai, 2016: Potential role of the February-March southern annular mode on the Indian summer monsoon rainfall: A new perspective. Climate Dyn., 47, 1161-1179, https://doi.org/10.1007/s00382015-2894-5.

Qiu, Y., H. Guo, Y. Ruan, X. Fu, L. Shi, and B. Tian, 2017a: A dataset of microwave brightness temperature and freeze-thaw for medium-to-large lakes over the High Asia region (2002-2016). China Sci. Data, 2 (2), https://doi.org/10.11922/csdata.170.2017.0117.

,,,,----- , and,$- 2017 \mathrm{~b}$ : Microwave brightness temperature and freeze-thaw datasets for medium-large lakes over the High Asia region (2002-2016). China Science Data Bank, https://doi.org/10.11922/sciencedb.374.

Rangwala, I., J. Miller, and M. Xu, 2009: Warming in the Tibetan Plateau: Possible influences of the changes in surface water vapor. Geophys. Res. Lett., 36, L06703, https://doi.org/10.1029/ 2009GL037245.

Rao, V. B., A. do Carmo, and S. Franchito, 2003: Interannual variations of storm tracks in the Southern Hemisphere and their connections with the Antarctic oscillation. Int. J. Climatol., 23, 1537-1545, https://doi.org/10.1002/joc.948.

Rayner, N., D. Parker, E. Horton, C. Folland, L. Alexander, D. Rowell, E. Kent, and A. Kaplan, 2003: Global analyses of sea surface temperature, sea ice, and night marine air temperature since the late nineteenth century. J. Geophys. Res., 108, 4407, https://doi.org/10.1029/2002JD002670.

Reason, C., and M. Rouault, 2005: Links between the Antarctic Oscillation and winter rainfall over western South Africa. Geophys. Res. Lett., 32, L07705, https://doi.org/10.1029/ 2005 GL022419.

Robertson, D., R. Ragotzkie, and J. Magnuson, 1992: Lake ice records used to detect historical and future climatic changes. Climatic Change, 21, 407-427, https://doi.org/10.1007/BF00141379.

Rouse, W., C. Oswald, J. Binyamin, C. Spence, W. Schertzer, P. Blanken, N. Bussières, and C. Duguay, 2005: The role of northern lakes in a regional energy balance. J. Hydrometeor., 6, 291-305, https://doi.org/10.1175/JHM421.1.

Sánchez-López, G., and Coauthors, 2015: The effects of the NAO on the ice phenology of Spanish alpine lakes. Climatic Change, 130, 101-113, https://doi.org/10.1007/s10584-015-1353-y.
Sen Gupta, A., and M. England, 2007: Coupled ocean-atmosphere feedback in the southern annular mode. J. Climate, 20, 36773692, https://doi.org/10.1175/JCLI4200.1.

Shaman, J., and E. Tziperman, 2005: The effect of ENSO on Tibetan Plateau snow depth: A stationary wave teleconnection mechanism and implications for the South Asian monsoons. J. Climate, 18, 2067-2079, https://doi.org/10.1175/JCLI3391.1.

Silvestri, G., and C. S. Vera, 2003: Antarctic Oscillation signal on precipitation anomalies over southeastern South America. Geophys. Res. Lett., 30, 2115, https://doi.org/10.1029/2003GL018277.

Su, F., X. Duan, D. Chen, Z. Hao, and L. Cuo, 2013: Evaluation of the global climate models in the CMIP5 over the Tibetan Plateau. J. Climate, 26, 3187-3208, https://doi.org/10.1175/ JCLI-D-12-00321.1.

Sun, J., 2010: Possible impact of the boreal spring Antarctic Oscillation on the North American summer monsoon. Atmos. Oceanic Sci. Lett., 3, 232-236, https://doi.org/10.1080/ 16742834.2010.11446870.

—, H. Wang, and W. Yuan, 2009: A possible mechanism for the co-variability of the boreal spring Antarctic Oscillation and the Yangtze River valley summer rainfall. Int. J. Climatol., 29, 1276-1284, https://doi.org/10.1002/joc.1773.

,$- \ldots$, and -2010 : Linkage of the boreal spring Antarctic Oscillation to the West African summer monsoon. J. Meteor. Soc. Japan, 88, 15-28, https://doi.org/10.2151/jmsj.2010-102.

Takaya, K., and H. Nakamura, 2001: A formulation of a phaseindependent wave-activity flux for stationary and migratory quasigeostrophic eddies on a zonally varying basic flow. J. Atmos. Sci., 58, 608-627, https://doi.org/10.1175/ 1520-0469(2001)058<0608:AFOAPI > 2.0.CO;2.

Thompson, D., and J. Wallace, 2000: Annular modes in the extratropical circulation. Part I: Month-to-month variability. J. Climate, 13, 1000-1016, https://doi.org/10.1175/15200442(2000)013<1000:AMITEC > 2.0.CO;2.

, S. Solomon, P. Kushner, M. England, K. Grise, and D. Karoly, 2011: Signatures of the Antarctic ozone hole in Southern Hemisphere surface climate change. Nat. Geosci., 4, 741-749, https://doi.org/10.1038/ngeo1296.

Todd, M., and A. Mackay, 2003: Large-scale climatic controls on Lake Baikal ice cover. J. Climate, 16, 3186-3199, https:// doi.org/10.1175/1520-0442(2003)016<3186:LCCOLB > 2.0.CO;2.

Trenberth, K., and J. Fasullo, 2013: An apparent hiatus in global warming? Earth's Future, 1, 19-32, https://doi.org/10.1002/ 2013EF000165.

Verdy, A., J. Marshall, and A. Czaja, 2006: Sea surface temperature variability along the path of the Antarctic circumpolar current. J. Phys. Oceanogr., 36, 1317-1331, https://doi.org/10.1175/ JPO2913.1.

Vihma, T., 2014: Effects of Arctic sea ice decline on weather and climate: A review. Surv. Geophys., 35, 1175-1214, https:// doi.org/10.1007/s10712-014-9284-0.

Wang, H., H. Chen, and J. Liu, 2015: Arctic sea ice decline intensified haze pollution in eastern China. Atmos. Oceanic Sci. Lett., 8, 1-9, https://doi.org/10.3878/AOSL20140081.

Wang, Z., Y. Wu, J. Chang, X. Zhang, and D. Peng, 2017: Temporal and spatial variation of lake ice phenology and its influencing factors in the Tibetan Plateau [in Chinese]. J. Beijing Univ. Technol., 43, 701-709.

Wu, R., S. Yang, S. Liu, L. Sun, Y. Lian, and Z. Gao, 2011: Northeast China summer temperature and North Atlantic SST. J. Geophys. Res., 116, D16116, https://doi.org/10.1029/2011JD015779.

Wu, Z., J. Dou, and H. Lin, 2015: Potential influence of the November-December Southern Hemisphere annular mode 
on the East Asian winter precipitation: A new mechanism. Climate Dyn., 44, 1215-1226, https://doi.org/10.1007/s00382014-2241-2.

Xie, S.-P., and Y. Tanimoto, 1998: A pan-Atlantic decadal climate oscillation. Geophys. Res. Lett., 25, 2185-2188, https://doi.org/ 10.1029/98GL01525.

_ and J. A. Carton, 2004: Tropical Atlantic variability: Patterns, mechanisms, and impacts. Earth's Climate: The Ocean-Atmosphere Interaction, Geophys. Monogr., Vol. 147, Amer. Geophys. Union, 121-142, https://doi.org/10.1029/147GM07.

Xu, W., L. Ma, M. Ma, H. Zhang, and W. Yuan, 2017: Spatialtemporal variability of snow cover and depth in the QinghaiTibetan Plateau. J. Climate, 30, 1521-1533, https://doi.org/ 10.1175/JCLI-D-15-0732.1.

Yang, K., H. Wu, J. Qin, C. Lin, W. Tang, and Y. Chen, 2014: Recent climate changes over the Tibetan Plateau and their impacts on energy and water cycle: A review. Global Planet. Change, 112, 79-91, https://doi.org/10.1016/j.gloplacha.2013. 12.001 .

Yao, T., and Coauthors, 2012: Different glacier status with atmospheric circulations in Tibetan Plateau and surroundings.
Nat. Climate Change, 2, 663-667, https://doi.org/10.1038/ nclimate1580.

Yao, X., L. Li, J. Zhao, M. Sun, J. Li, P. Gong, and L. An, 2016: Spatial-temporal variations of lake ice phenology in the Hoh Xil region from 2000 to 2011. J. Geogr. Sci., 26, 70-82, https:// doi.org/10.1007/s11442-016-1255-6.

Zhang, G., Y. Zhang, J. Dong, and X. Xiao, 2013: Green-up dates in the Tibetan Plateau have continuously advanced from 1982 to 2011. Proc. Natl. Acad. Sci. USA, 110, 4309-4314, https:// doi.org/10.1073/pnas.1210423110.

Zhu, L., J. Jin, X. Liu, L. Tian, and Q. Zhang, 2017: Simulations of the impact of lakes on local and regional climate over the Tibetan Plateau. Atmos.-Ocean, 56, 230-239, https://doi.org/ 10.1080/07055900.2017.1401524.

Zhu, Y., 2009: The Antarctic oscillation-East Asian summer monsoon connections in NCEP-1 and ERA-40. Adv. Atmos. Sci., 26, 707-716, https://doi.org/10.1007/s00376-009-8196-2.

Zuo, J., W. Li, C. Sun, L. Xu, and H.-L. Ren, 2013: Impact of the North Atlantic sea surface temperature tripole on the East Asian summer monsoon. Adv. Atmos. Sci., 30, 1173-1186, https://doi.org/10.1007/s00376-012-2125-5. 